\title{
MHC class II expression and potential antigen-presenting cells in the retina during experimental autoimmune uveitis
}

\author{
Deborah A. Lipski ${ }^{1,2^{*}}$ (D), Rémi Dewispelaere ${ }^{1,3+}{ }^{+}$, Vincent Foucart ${ }^{1,3,4}$, Laure E. Caspers ${ }^{3}$, Matthieu Defrance ${ }^{5}$, \\ Catherine Bruyns ${ }^{1}$ and François Willermain ${ }^{1,3,4}$
}

\begin{abstract}
Background: Controversy exists regarding which cell types are responsible for autoantigen presentation in the retina during experimental autoimmune uveitis (EAU) development. In this study, we aimed to identify and characterize the retinal resident and infiltrating cells susceptible to express major histocompatibility complex (MHC) class II during EAU.

Methods: EAU was induced in C57BL/6 mice by adoptive transfer of autoreactive lymphocytes from IRBP1-20-immunized animals. MHC class II expression was studied by immunostainings on eye cryosections. For flow cytometry (FC) analysis, retinas were dissected and enzymatically digested into single-cell suspensions. Three MHC class $\mathrm{II}^{+}$retinal cell populations were sorted by FC, and their RNA processed for RNA-Seq.

Results: Immunostainings demonstrate strong induction of MHC class II expression in EAU, especially in the inner retina at the level of inflamed vessels, extending to the outer retinal layers and the subretinal space in severely inflamed eyes. Most MHC class $\|^{+}$cells express the hematopoietic marker IBA1. FC quantitative analyses demonstrate that MHC class II induction significantly correlates with disease severity and is associated with upregulation of co-stimulatory molecule expression. In particular, most MHC class $\|^{\text {hi }}$ cells express co-stimulatory molecules during EAU. Further phenotyping identified three $\mathrm{MHC}$ class $\|^{+}$retinal cell populations: $\mathrm{CD}^{-} 5^{-} \mathrm{CD} 11 \mathrm{~b}^{-}$non-hematopoietic cells with low $\mathrm{MHC}$ class II expression and $\mathrm{CD}_{4} 5^{+} \mathrm{CD} 11 \mathrm{~b}^{+}$hematopoietic cells with higher MHC class II expression, which can be further separated into $\mathrm{Ly}_{6 \mathrm{C}^{+}}$and $\mathrm{Ly} 6 \mathrm{C}^{-}$cells, possibly corresponding to infiltrating macrophages and resident microglia. Transcriptome analysis of the three sorted populations leads to a clear sample clustering with some enrichment in macrophage markers and microglial cell markers in $\mathrm{Ly}_{6 \mathrm{C}}{ }^{+}$and $\mathrm{Ly}_{6 \mathrm{C}} \mathrm{C}^{-}$cells, respectively. Functional annotation analysis reveals that both hematopoietic cell populations are more competent in MHC class II-associated antigen presentation and in T cell activation than non-hematopoietic cells.
\end{abstract}

Conclusion: Our results highlight the potential of cells of hematopoietic origin in local antigen presentation, whatever their Ly6C expression. Our work further provides a first transcriptomic study of MHC class II-expressing retinal cells during EAU and delivers a series of new candidate genes possibly implicated in the pathogenesis of retinal autoimmunity.

Keywords: Autoimmune eye disorders, Inflammation, Blood-retinal barrier, Antigen presentation, Co-stimulatory molecules, Microglia, Macrophages, Ly6C, Transcriptome, RNA-Seq

\footnotetext{
* Correspondence: dlipski@ulb.ac.be

${ }^{\dagger}$ Equal contributors

'Ophthalmology Group, IRIBHM (Institut de Recherche Interdisciplinaire en

Biologie Humaine et Moléculaire), Université Libre de Bruxelles (ULB), Erasme

Campus, Building C, Room C6.117, 808 Route de Lennik, 1070 Brussels,

Belgium

${ }^{2}$ Ophthalmology Department of Erasme Hospital, Université Libre de

Bruxelles (ULB), 808 Route de Lennik, 1070 Brussels, Belgium

Full list of author information is available at the end of the article
} 


\section{Background}

The major histocompatibility complex $(\mathrm{MHC})$ is a set of cell surface proteins divided into two major groups respectively known as class I and class II molecules, which play a fundamental role in adaptive immunity. While MHC class I is ubiquitously expressed by almost all cells, MHC class II is mostly expressed by antigenpresenting cells (APCs) such as monocytes, macrophages, and dendritic cells. These cells are involved in external antigen (Ag) processing and antigenic peptide presentation in the context of MHC class II to CD4+ T helper $\left(\mathrm{T}_{\mathrm{H}}\right)$ cells. Full $\mathrm{T}_{\mathrm{H}}$ cell activation occurs when the peptide-MHC class II complex interacts with the $\mathrm{T}$ cell receptor (TCR), in the presence of signals delivered by the interaction of co-stimulatory molecules such as CD40, CD80, and CD86 on the APC and their ligands on $\mathrm{T}$ cells.

Interestingly, expression of MHC class II is not strictly restricted to immune cells. It has been demonstrated that non-professional APCs are capable of inducible $\mathrm{MHC}$ class II expression, Ag presentation, and even effective $\mathrm{T}$ cell reactivation $[1,2]$. Aberrant expression of MHC class II by non-professional APCs from targeted organs and subsequent presentation of auto-Ags is now considered to be an important mechanism in the pathogenesis of autoimmune disease processes, including those affecting the eye $[3,4]$.

Experimental autoimmune uveitis (EAU) is a model of organ autoimmunity in the eye. EAU is mediated by activated $T_{H}$ cells, which are believed to be central in the pathogenesis of human non-infectious uveitis as well $[5,6]$. Immunization with IRBP in adjuvant context leads to priming of autoreactive $\mathrm{T}$ cells in peripheral lymphoid organs and polarization into $\mathrm{T}_{\mathrm{H}} 1$ and $\mathrm{T}_{\mathrm{H}} 17$ cells. These activated $\mathrm{T}_{\mathrm{H}}$ cells then home to the eye, where they induce blood-retinal barrier (BRB) breakdown and subsequent massive recruitment of diverse inflammatory leukocytes from the circulation [7]. It has been shown that while the first activated $\mathrm{T}$ cells enter the eye by chance, regardless of their specificity for retinal or non-retinal Ags, only retina-specific $\mathrm{T}$ cells induce EAU [8,9]. This leads to the conclusion that EAU induction requires $T_{H}$ cell restimulation by in situ Ag recognition. However, the main targets in IRBPinduced EAU are the photoreceptors, which are not believed to express MHC class II. In this context, a tremendous series of works have tried to determine which cell types are responsible for intra-ocular Ag presentation during EAU. Both resident retinal cells [10] and infiltrating hematopoietic cells [11] have been proposed, with inconsistent results.

In this study, we aimed to identify and characterize the retinal resident and infiltrating cells susceptible to express $\mathrm{MHC}$ class II during adoptive transfer (AT) EAU.

\section{Methods}

\section{Reagents and animals}

Interphotoreceptor retinoid-binding peptide (IRBP) 1-20 (GPTHLFQPSLVLDMAKVLLD), representing residues 1-20 of human IRBP, was synthesized by New England Peptide (Gardner, MA, USA). Pertussis toxin (PTX) and complete Freund's adjuvant (CFA) were purchased from Sigma-Aldrich (Bornem, Belgium). Pathogen-free female C57BL/6 mice (6 to 10 weeks old), purchased from Janvier (Genest St Isle, France) were housed at the animal facilities in accordance with the European guidelines. Animal treatment conformed to the ARVO Statement for the Use of Animals in Ophthalmic and Vision Research. All cells were cultured in RPMI 1640 medium supplemented with 25 mM HEPES, 10\% fetal bovine serum, 1\% L-glutamine, $1 \%$ sodium-pyruvate, $100 \mathrm{IU} / \mathrm{ml}$ penicillin, $100 \mathrm{~g} / \mathrm{ml}$ streptomycin, $5.10^{-5} \mathrm{M} \beta$-mercaptoethanol in a $5 \% \mathrm{CO}$, and $95 \%$ humidity incubator.

\section{Classical and adoptive transfer models of experimental autoimmune uveitis}

Classical EAU was induced by immunization of naive C57BL/6 mice with a subcutaneous injection in each hind leg of $50 \mu \mathrm{l}$ of a mixture containing $500 \mu \mathrm{g} / 100 \mu \mathrm{l}$ IRBP peptide $1-20$ in a 1:1 emulsion with CFA enriched with $2.5 \mathrm{mg} / \mathrm{ml}$ of heat-inactivated mycobacterium tuberculosis. All animals simultaneously received an intraperitoneal injection of $1 \mu \mathrm{g}$ of PTX. Adoptive transfer EAU was induced by AT of autoreactive lymphocytes following the protocol of Shao $\mathrm{H}$ et al. [12]. Briefly, animals were immunized as mentioned above. Twelve days after immunization, mice were euthanized and their spleen and draining lymph nodes dissected and dissociated. Spleen cell suspensions were enriched in T lymphocytes through passage on nylon wool fiber columns, then pooled with total lymph node cells and restimulated in vitro with IRBP1-20 $(1 \mu \mathrm{g} / \mathrm{ml})$. After 2 days in culture, cells were injected intraperitoneally into naive C57BL/6 mice $\left(5 \times 10^{6}\right.$ cells/mouse $)$.

\section{Disease grading}

A clinical grading was performed at day 14 or day 21 after disease induction. Mice were anesthetized by a 50 $\mu \mathrm{l}$ intraperitoneal injection of a Rompun (0.2\%) and Ketalar $(20 \mathrm{mg} / \mathrm{ml})$ mixture. The pupils were dilated with tropicamid $(5 \mathrm{mg} / \mathrm{ml})$ and phenylephrine $(1.5 \mathrm{mg} / \mathrm{ml})$, and the eyes were examined under the slit-lamp of a surgical microscope (Zeiss, Göttingen, Germany) by using a cover slip coated in a viscoelastic gel (synthetic polymer of acrylic acid $2 \mathrm{mg} / \mathrm{g}$, Vidisic, Tramedico, Belgium) and positioned on the cornea. The clinical grading was performed independently by two ophthalmologists, based on a system adapted from $\mathrm{Xu}$ et al. [13]. Briefly, vitritis, optic neuropathy, retinitis, and 
vasculitis were separately scored in each eye, from 0 (no disease) to 4 (highly severe disease) with half-point increments and averaged to generate the clinical score of the eye on a scale from 1 to 4 . The clinical score attributed to one mouse corresponds to the mean of the scores of the two eyes.

\section{Immunohistology \\ Immunofluorescence stainings on retinal cryosections}

At day 14 or 21 after disease induction, the eyes were collected, prefixed for $6 \mathrm{~h}$ at $4{ }^{\circ} \mathrm{C}$ in PFA (paraformaldehyde) $4 \%$ and sucrose $3 \%$, and then put in three successive baths containing 5,10 , and $18 \%$ sucrose in PBS, respectively, for $24 \mathrm{~h}$ each. The entire eyes were embedded in OCT medium (Sakura, Antwerp, Belgium) and cut in 16- $\mu$ m-thick frozen sections using a cryostat (CM3050S Leica). The MOM (mouse-on-mouse) Basic Kit (Vector Laboratories, Labconsult, Brussels) was used to prevent high background staining. Cryosections were fixed with PFA $4 \%$ for 15 min and blocked in TBS (Tris $10 \mathrm{mM}, \mathrm{NaCl} 0.9 \%, \mathrm{pH}$ 7.6) supplemented with MOM IgG blocking solution and Triton $0.3 \%$ for $2 \mathrm{~h}$. Sections were incubated overnight with the following primary antibodies, alone or in different combinations as indicated in the results: anti-MHC class II (rat, 1/200; BD Biosciences, Erembodegem, Belgium), anti-GFAP (mouse, 1/500; Millipore, Brussels, Belgium), anti-endoglin (goat, 3/ 500; BD Biosciences), anti-CD31 (goat, 1/200, R\&D systems, Abingdon), and anti-IBA1 (goat, 1/100, Abcam, Cambridge, UK), diluted in TBS supplemented with MOM kit protein concentrate. After three washings in TBS, the sections were incubated in the dark for $1 \mathrm{~h} 30$ with species-specific secondary antibodies coupled to different fluorochromes, as indicated in data, then with Hoechst to stain the nuclei (Invitrogen, Gent, Belgium). After several washings, the sections were mounted in Glycergel (Dako, Agilent Technologies, Diegem, Belgium) supplemented with 2.5\% Dabco (Sigma-Aldrich). Pictures of immunostainings were acquired using an Axiolmager Z1 microscope equipped with an AxioCamMR camera (Carl Zeiss, Inc.) using the z-stack mode of the Axiovision acquisition software. Z-stacks were processed using the Imaris deconvolution software. Differential interference contrast (DIC) images were recorded on an AxioImager Z1 (Zeiss) upright widefield microscope using a Plan Apochromat 20x $\backslash 0.8$ NA (Zeiss) air objective combined with the corresponding EC PN (II) prism slider (Zeiss) under the objective and polarizing filters in the light path.

\section{Immunofluorescence stainings on retinal wholemount preparations}

At day 21 after disease induction, the eyes were collected and immediately immersed in PFA $4 \%$ for $1 \mathrm{~h}$ at $4{ }^{\circ} \mathrm{C}$. The eyes were then dissected in ice-cold PBS: the anterior segment of the globe, crystalline lens, and vitreous were removed and the retina was carefully peeled from the retinal pigment epithelium. Whole retinas were fixed in 70\% ethanol for $1 \mathrm{~h}$, rinsed three times in PBS (10 min each), blocked with a solution containing 3\% milk and 3\% bovine serum albumin in PBS for $1 \mathrm{~h}$ and incubated with anti-MHC class II (rat, 1/200; BD Biosciences, Erembodegem, Belgium) and anti-endoglin (goat, 1/200; BD Biosciences) antibodies in a PBS-BSA1\% solution overnight at room temperature. The retinas were rinsed three times in PBS (20 min each) and incubated sequentially for $1 \mathrm{~h}$ with each secondary antibody. After three final washings in PBS (20 min each), each retina was flattened by radial incisions and mounted with Vectashield antifade mounting medium with DAPI (Labconsult, Brussels).

\section{Preparation of retinal single-cell suspensions}

Mice were sacrificed at day 14 or 21 after disease induction, and the eyes immediately enucleated. Eyes were carefully hemisected in HBSS buffer containing penicillin/streptomycin $1 \%$, with surgical scissors under a surgical microscope. Retinal tissue was isolated and rinsed in HBSS medium. The two retinas of each mouse were pooled and cut into small pieces before enzymatic digestion in $3 \mathrm{ml}$ HBSS containing $1.6 \mathrm{mg} / \mathrm{ml}$ Liberase (Roche, Vilvoorde, Belgium) and $0.1 \mathrm{mg} / \mathrm{ml}$ DNase I (Sigma-Aldrich) at $37{ }^{\circ} \mathrm{C}$ for $45 \mathrm{~min}$. Cell dissociation was stimulated by pipetting every $15 \mathrm{~min}$. Cells were washed with DMEM/10\% FBS and filtered through a $40-\mu \mathrm{m}$ cell strainer to obtain a single-cell suspension [14]. The yield was approximately 2 to 3 million retinal cells per mouse.

\section{Fluorescence-activated cell sorting (FACS) analysis}

Retinal single-cell suspensions were tested by flow cytometry (FC) for their membrane expression of $\mathrm{MHC}$ class II (I-A/I-E), CD45 (pan-leucocyte marker), CD11b (myeloid cell marker), Ly6C (monocyte/macrophage marker), CD31 (endothelial cell marker), CD40, CD80 and CD86 (co-stimulatory molecules), and F4/80 (panmacrophage marker) using specific antibodies (BD Biosciences) coupled to different fluorochromes. For Lipocalin 2 (Lcn2) and Cysteinyl Leukotriene Receptor 1 (Cysltr1), unconjugated primary antibodies (from R\&D systems and Abcam, respectively) and species-specific secondary antibodies coupled to Alexa488 were used. Cells were incubated with the relevant antibodies for 20 min at $4{ }^{\circ} \mathrm{C}$, washed and resuspended in FACS buffer. For Lcn2 intracytoplasmic staining, cells were first incubated with membrane antibodies then permeabilized with Cytofix/cytoperm fixation/permeabilization solution (BD Biosciences) before incubation with the anti-Lcn2 antibody. Live cells were gated with Hoechst $1 / 4000$ and 
debris and doublets were excluded (the complete gating strategy is illustrated in Additional file 1: Figure S1). Up to one million total cells per sample were analyzed on a LSR-Fortessa flow cytometer using the CellQuest Software (BD Biosciences). Isotypes and Fluorescence minus one (FMO) controls were used for accurate gating. Compensations were performed using BD CompBeads (BD Biosciences).

\section{Analysis of retinal cell gene expression \\ Purification of different MHC class $\mathrm{II}^{+}$populations}

Three weeks after AT, mice were sacrificed and retinal single-cell suspensions prepared as described above. Cells were stained with PE-labeled anti-MHC class II, PECy7-labeled anti-CD45, FITC-labeled anti-CD11b and APC-labeled anti-Ly6C antibodies. MHC class $\mathrm{II}^{+} \mathrm{CD} 45$ ${ }^{+} \mathrm{CD} 11 \mathrm{~b}^{+} \mathrm{Ly} 6 \mathrm{C}^{+}$cells (referred to as Plus), MHC class II ${ }^{+} \mathrm{CD} 45^{+} \mathrm{CD} 11 \mathrm{~b}^{+} \mathrm{Ly} 6 \mathrm{C}^{-}$cells (referred to as Minus), and $\mathrm{MHC}$ class $\mathrm{II}^{+} \mathrm{CD} 45^{-} \mathrm{CD} 11 \mathrm{~b}^{-} \mathrm{Ly}^{-} \mathrm{C}^{-}$(referred to as nonhematopoietic or $\mathrm{NH}$ ) were separately sorted by preparative FC using a FACSAria with the FACSDiva Software (BD). Due to the low cell number obtained from each mouse (around 1000 Plus cells), three mice were pooled to generate each sample. Cells were sorted directly in lysis buffer, vortexed for $30 \mathrm{~s}$ and flash frozen in liquid nitrogen. The purity of the sorted cell populations was evaluated by FC re-analysis of sorted cells (Additional file 2: Figure S2).

\section{RNA extraction}

RNA extraction was performed using the MiRNeasy MicroKit (Qiagen) according to the manufacturer's recommendations and a DNase step to avoid DNA contamination. RNA quality was assessed using the Agilent 2100 Bioanalyzer with RNA 6000 Pico kit (Agilent Technologies).

\section{RNA processing and RNA sequencing}

Indexed cDNA libraries were prepared using the Ovation Single Cell RNAseq system (Nugen). The multiplexed libraries were loaded and sequences were produced using a TruSeq PE cluster and SBS-kit on a HiSeq 1500 (Illumina). Approximately 25 million paired-end reads/sample were mapped against the mouse reference genome (NCBI Build 37/UCSC mm9) using STAR software to generate read alignments for
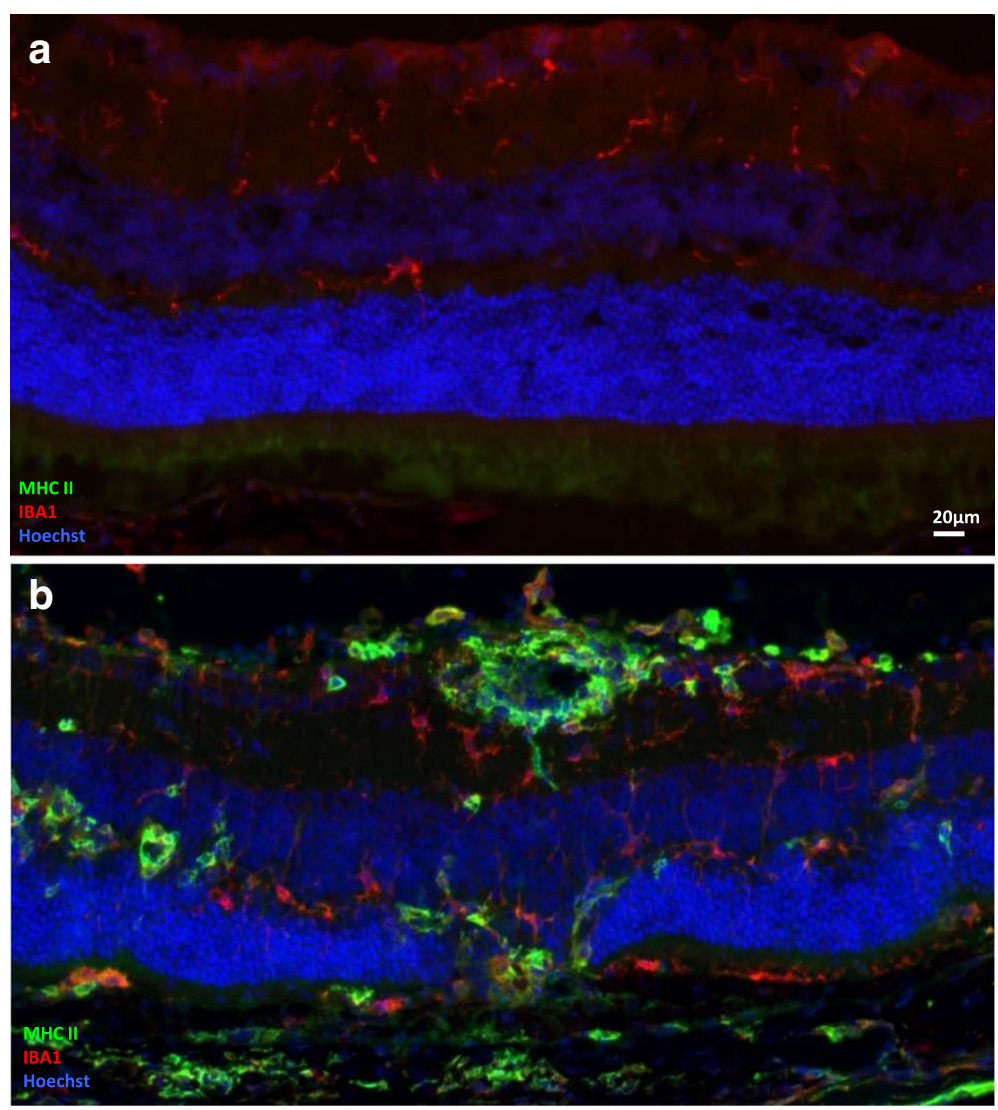

Fig. $1 \mathrm{MHC}$ class II retinal expression is highly induced during EAU. Three weeks after adoptive transfer, eye cryosections were prepared and stained for MHC class II (green) and IBA1 (red) detection. Naive eyes were used as control. Cell nuclei were stained with Hoechst (blue). Each picture was chosen as representative of an experiment conducted on three or more animals. a Naive retina. b Adoptive transfer EAU retina (grade 3.5) 
each sample. Expression levels were quantified using the featureCounts [15] tool and the UCSC RefSeq gene annotation as a reference (exons only, genes as meta features). Differential analysis between the groups was performed using the EdgeR package (quasi-likelihood F-tests). Normalized expression levels were estimated using the EdgeR rpm function and converted to $\log _{2}$ FPKM (fragments per kilobase of exon per million mapped reads) after resetting low FPKMs to 1 . To perform blind clustering analysis, genes were selected based on the overall variance between samples (independently of their category), by keeping only the 30 most variant ones. Functional analysis was performed using the DAVID web-based functional annotation tool [16].

\section{Statistical analysis}

Statistical analysis was performed using Kruskal-Wallis, ANOVA, Tukey post-hoc multiple comparisons test, and Student's $t$ test. Only $p$ values $<0.05$ were considered statistically significant.
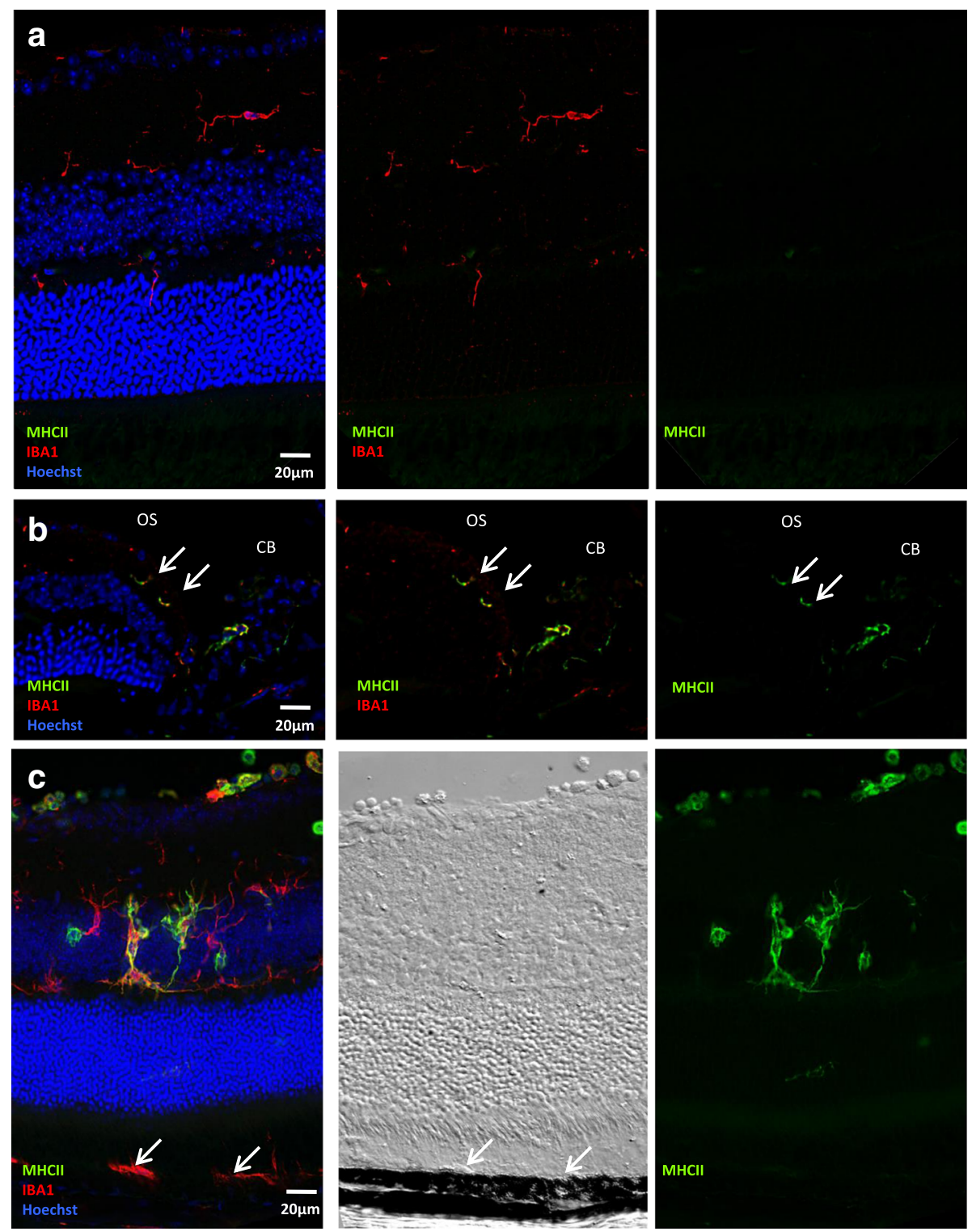

Fig. 2 MHC class II expression in the neural retina. Three weeks after adoptive transfer, EAU eye cryosections were prepared and stained for MHC class II (green) and IBA-1 (red) detection. Naive eyes were used as control. Cell nuclei were stained with Hoechst (blue). Each picture was chosen as representative of an experiment conducted on three or more animals. The differential interference contrast (DIC) image was added to localize the RPE more precisely. a Expression of MHC class $\|$ and IBA1 in the naive retina. $\mathbf{b}$ Expression of MHC class II and IBA1 in the naive retina at the ora serrata (OS, arrows), adjacent to the ciliary body (CB). c Expression of MHC class II and IBA1 during EAU and corresponding DIC image (arrows point to IBA ${ }^{+}$cells at the level of the RPE layer) 


\section{Results}

Immunofluorescence analysis of MHC class II expression during EAU

Naive or EAU eyes enucleated 21 days after AT were prepared for MHC class II expression analysis by immunofluorescence (IF). As compared to naive mice, MHC class II expression in the retina is much more intense and extended during EAU (Fig. 1). Most MHC class II-bearing cells co-stain with IBA1, a marker classically used to identify macrophages and microglia (quantification of simple and double-stained cells is provided in Additional file 3: Figure S3). Whereas in naive mice, IBA1-expressing microglial cells are confined to the inner retina (Fig. 1a), during severe uveitis microglial radial processes extending from the outer plexiform layer into the outer nuclear layer $(\mathrm{ONL})$, with
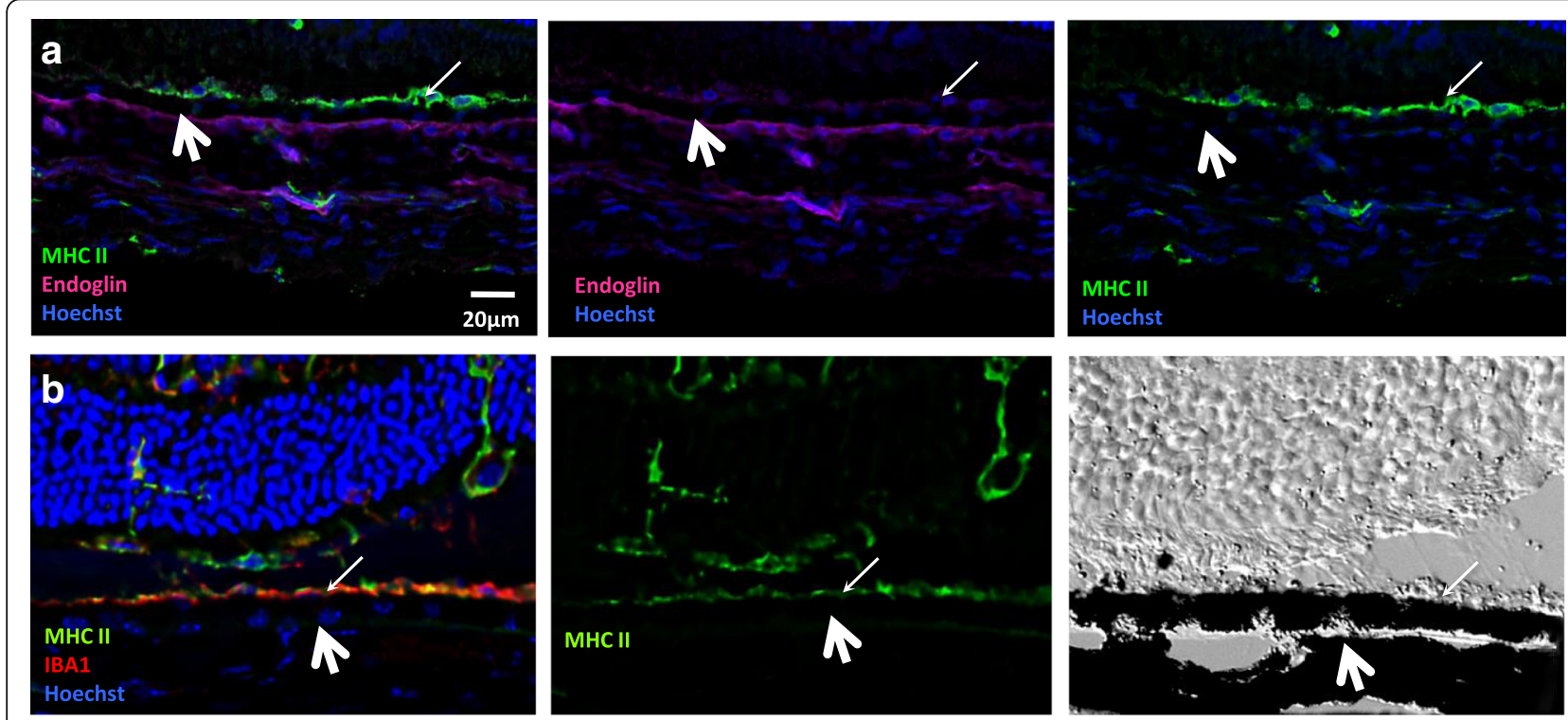

C
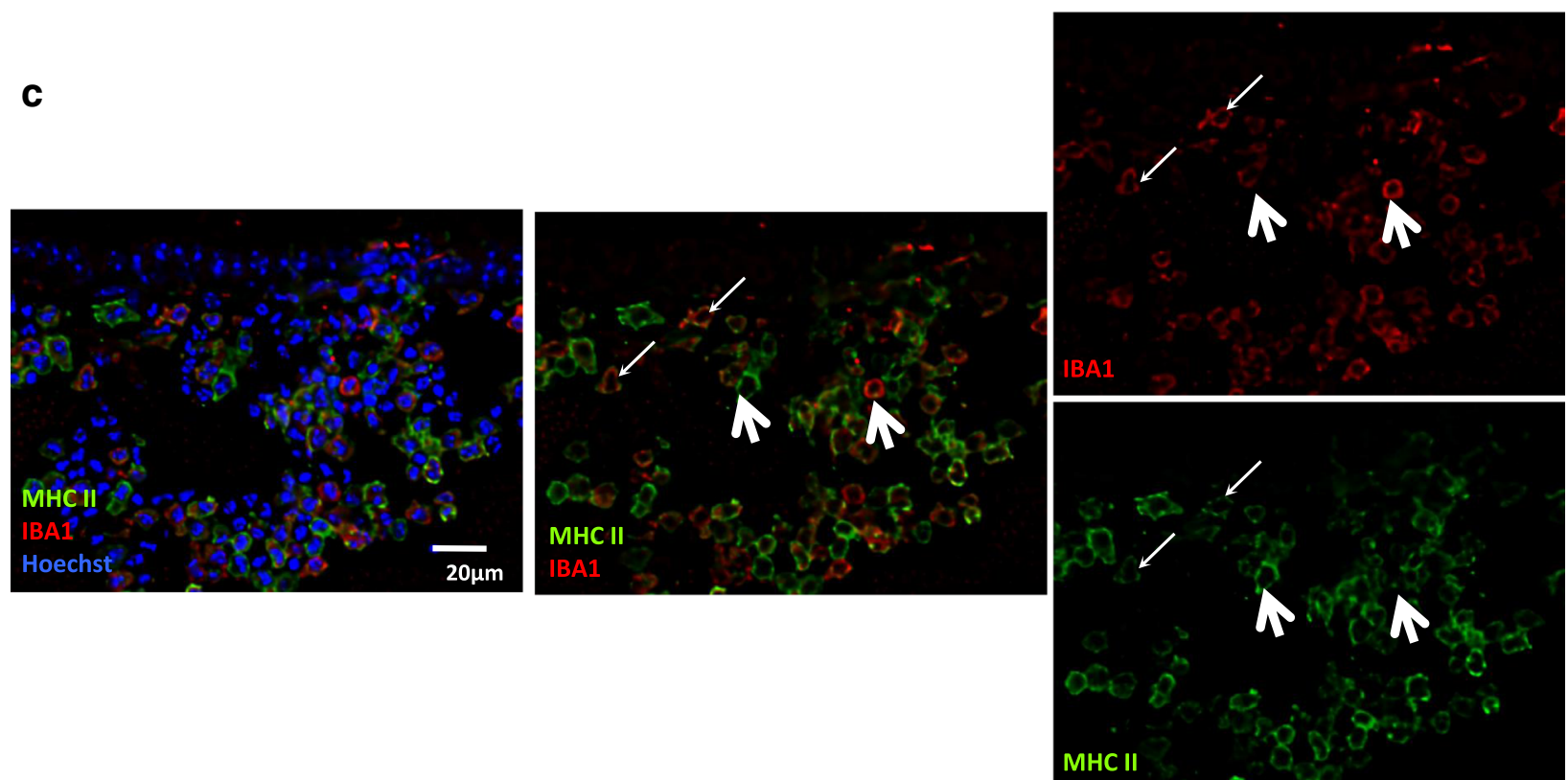

Fig. $3 \mathrm{MHC}$ class II is expressed at the level of the RPE layer and by cells infiltrating the vitreous. Three weeks after adoptive transfer, EAU eye cryosections were prepared and stained for MHC class II (green), IBA1 (red), or endoglin (magenta) detection. Cell nuclei were stained with Hoechst (blue). Each picture was chosen as representative of an experiment conducted on three or more animals. The DIC image was added to localize the RPE more precisely. a MHC class II and endoglin expression in the RPE region. Thin arrows point to the RPE layer, and thick arrows indicate choroidal vessels stained with endoglin. $\mathbf{b}$ MHC class II and IBA1 expression in the RPE region and corresponding DIC image. Thin arrows point to the RPE layer, and thick arrows indicate the choroid. c MHC class II and IBA1 expression by cells infiltrating the vitreous. Thin arrows indicate cells positive for both markers, and thick arrows point to cells positive for only one marker 
concurrent photoreceptor death and ONL thinning (Fig. 1b). We also analyzed the expression of MHC class II during classical EAU at disease peak (day 21) as well as during AT EAU induction (day 14). Representative images are included in Additional file 3: Figure S3 and Additional file 4: Figure S4. No difference was observed regarding MHC class II expression in classical
EAU compared to AT EAU matched for disease grade. Not all animals show signs of uveitis at day 14 after AT. We processed the eyes from three independent animals with signs of disease and three independent animals with normal fundus appearance for IF stainings. When no signs of EAU appearing in the fundus, IF images were quite similar to what are observed in naïve eyes,

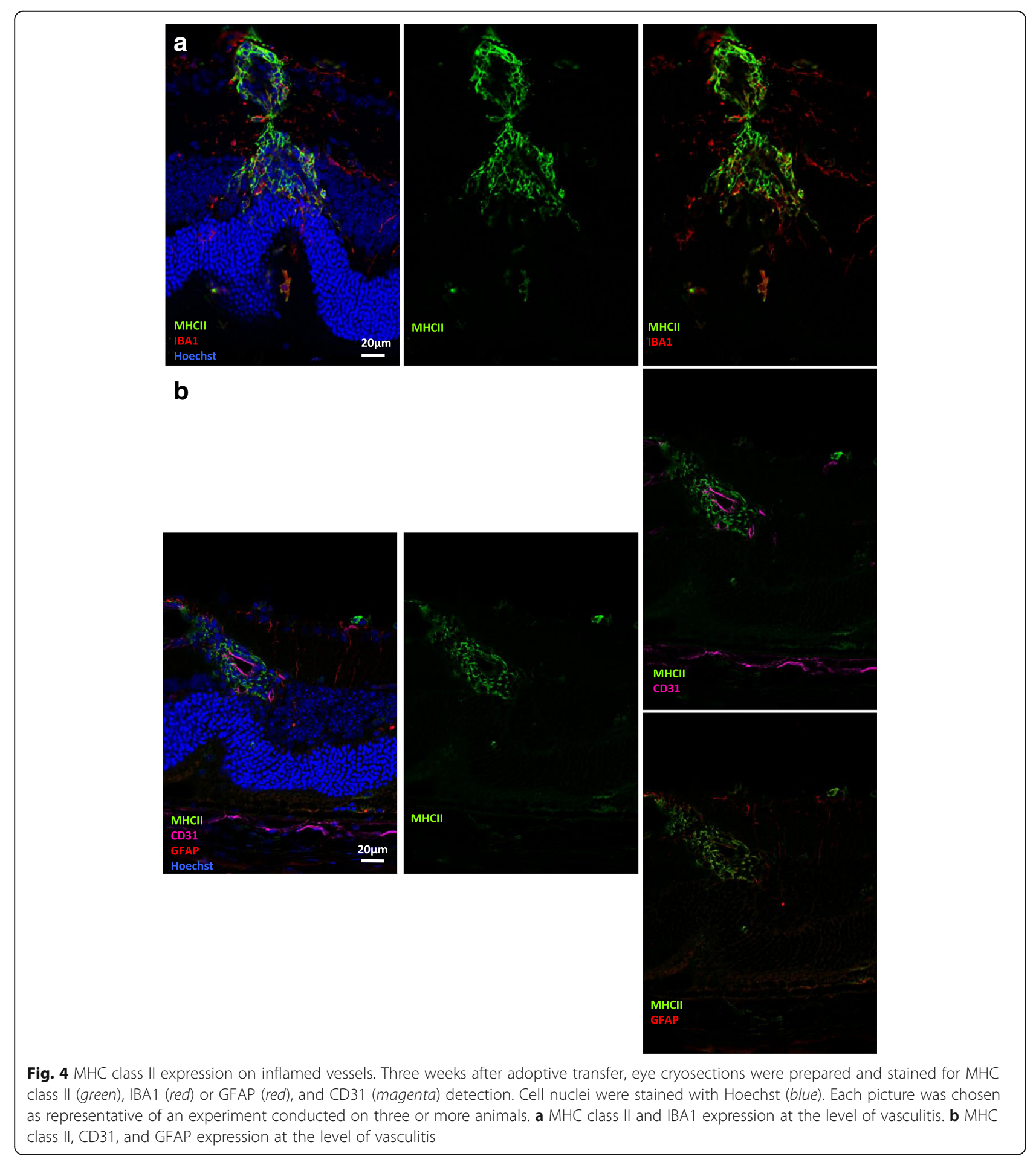




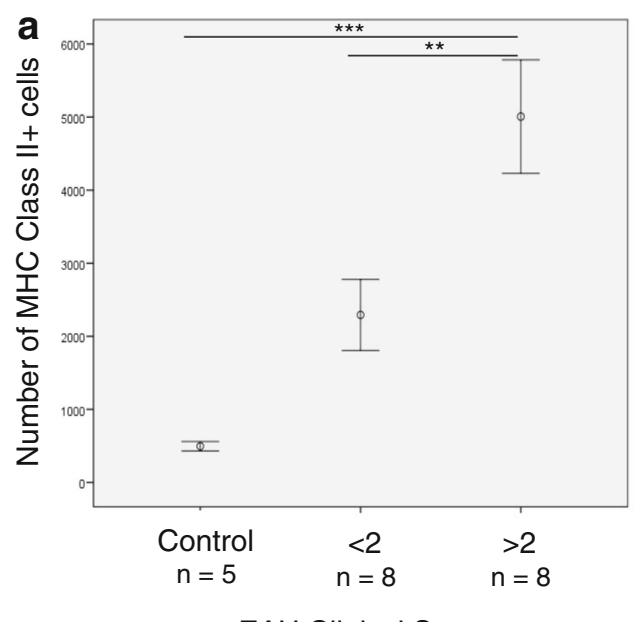

\section{EAU Clinical Score}
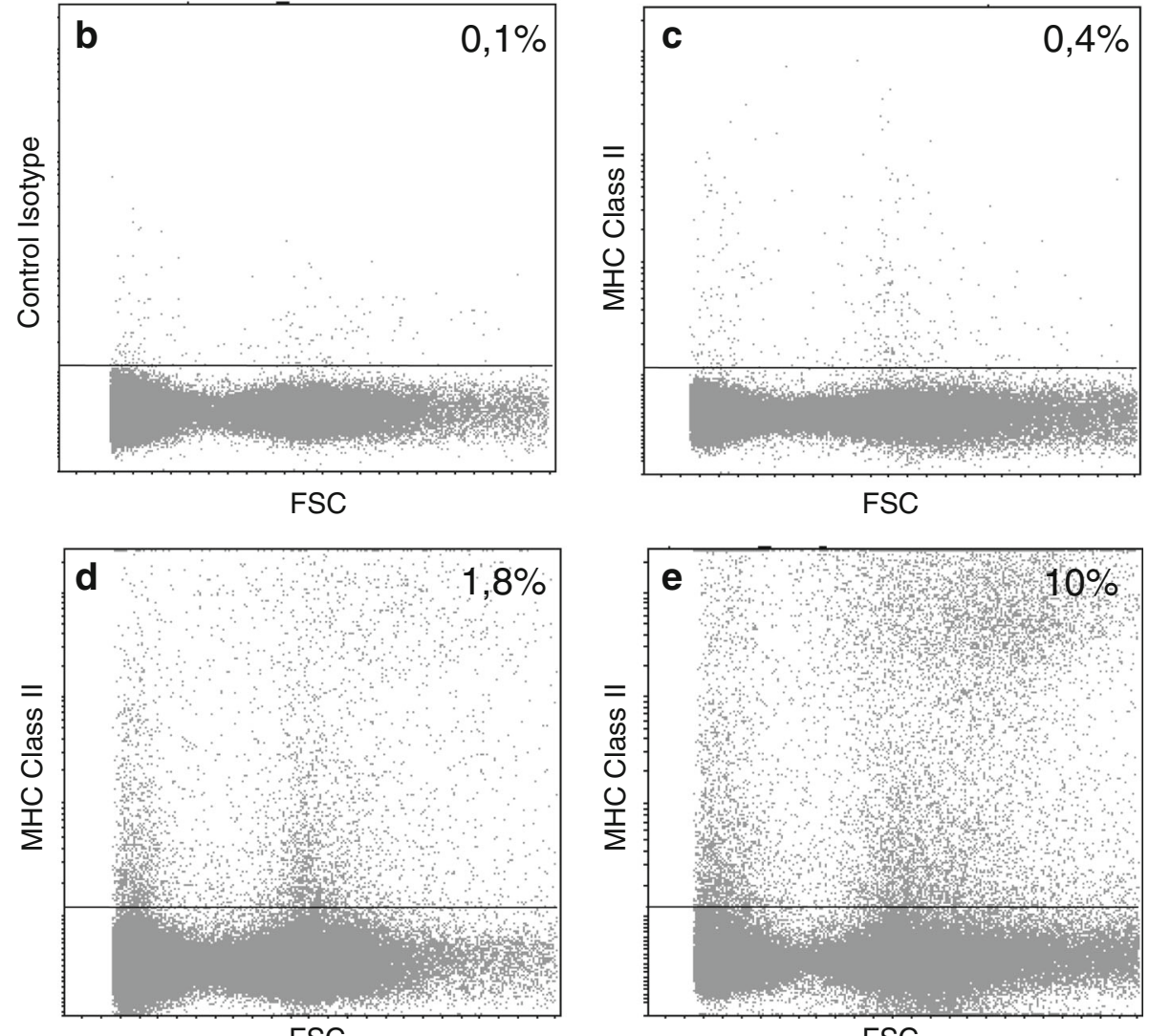

FSC

Fig. $5 \mathrm{MHC}$ class II expression correlates to EAU severity. Three weeks after adoptive transfer, retinas were carefully dissected, cut into small pieces, and dissociated by incubation with Liberase DL and DNase I at $37^{\circ} \mathrm{C}$ for $45 \mathrm{~min}$. Naive eyes were used as control. The single-cell suspensions, excluding dead cells (DAPI+) were analyzed by flow cytometry for MHC II expression using fluorochrome-conjugated specific antibodies. For Figures B to $E$, data are from 1 representative mouse out of 21 independent mice (5 control, 8 low-score EAU and 8 high-score EAU mice). a Number of MHC class II-expressing cells (normalized per 1 million analyzed retinal cells) for different EAU clinical scores. Data represented: mean \pm SEM, ANOVA, and Tukey post-hoc multiple comparisons test, ${ }^{* *} p<0.01,{ }^{* * *} p<0.001$. b Naive eye with control isotype. c MHC class II expression in the naive retina. $\mathbf{d} \mathrm{MHC}$ class II expression in the retina during moderate uveitis (clinical grade 1). e MHC class II expression in the retina during severe uveitis (clinical grade 4) 


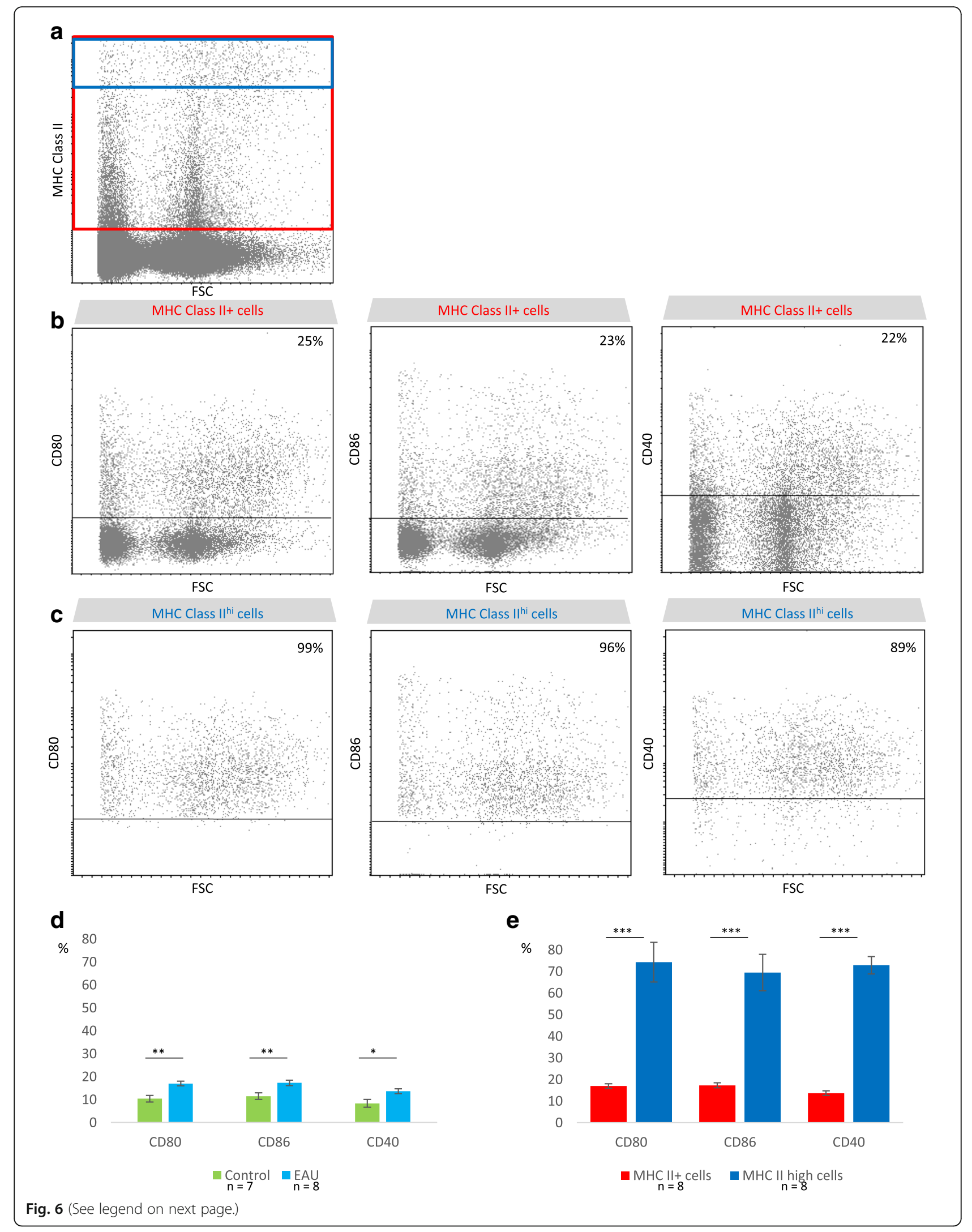


(See figure on previous page.)

Fig. $6 \mathrm{MHC}$ class II ${ }^{+}$cells upregulate co-stimulatory molecule expression during EAU. Three weeks after adoptive transfer, the retinas were carefully dissected, cut into small pieces, and dissociated by enzymatic digestion. Naive eyes were used as control. The single-cell suspensions, excluding dead cells (DAPI+) were analyzed by flow cytometry for MHC class II, CD40, CD80, and CD86 expression using fluorochrome-conjugated specific antibodies. Data are from one representative mouse (clinical grade 3.75) out of four independent experiments involving eight independent EAU animals. Statistical analysis was performed using $t$ tests, ${ }^{*} p$ value $<0.05,{ }^{* *} p$ value $<0.01,{ }^{* * *} p<0.001$. a Gating on MHC class $\|^{+}$(red gate) and MHC class $\|^{\text {hi }}$ (blue gate) cells. $\mathbf{b}$ Expression of co-stimulatory molecules by MHC class $\|^{+}$cells. $\mathbf{c}$ Expression of co-stimulatory molecules by MHC class $\|^{\text {hi }}$ cells. $\mathbf{d}$ Histogram representation of the mean percentage of co-stimulatory molecule expression by MHC class $\|^{+}$cells in naive versus EAU retinas. Mean \pm SEM (unpaired $t$ test). e Histogram representation of the mean percentage of co-stimulatory molecule expression by $\mathrm{MHCI}^{\text {hi }}$ versus MHC class $\|^{+}$cells during EAU. Mean \pm SEM (paired samples $t$ test)

with very discrete expression of MHC class II around the optic nerve and at the ora serrata (data not shown). When signs of disease were present, IF images were very evocative of stainings at day 21 .

\section{MHC class II expression in the neural retina}

In naive eyes, most neural retina is devoid of MHC class $\mathrm{II}^{+}$cells (Fig. 2a). Weak expression by dendriform cells is occasionally found around inner retinal vessels, especially surrounding the optic nerve (data not shown). MHC class II expression is systematically found at the level of the ciliary body, extending to the ora serrata in the form of rare dendriform cells, co-stained with IBA1 (Fig. 2b, white arrows). During EAU, microglial cells adopt an activated morphology with larger cell bodies and amoeboid processes (Fig. 2c) and MHC class II expression develops in dendriform cells mostly spanning from the inner plexiform layer to the outer plexiform layer and eventually invading the ONL. It is noticeable that IBA1 staining is more extensive than MHC class II staining and that not all $\mathrm{IBA}^{+}$cells express MHC class II (Fig. 2c and Additional file 3: Figure S3D). Surprisingly, IBA1 is expressed at the level of the retinal pigment epithelium (RPE) layer; although, DIC imaging suggests that this expression corresponds to IBA1+ hematopoietic cells adhering to the RPE rather than to the RPE cells themselves (Fig. 2c).

\section{MHC class II expression at the level of the RPE and on cells infiltrating the vitreous}

Sparse expression of MHC class II is found at the level of the RPE layer (Fig. 3a, b, thin arrows), right above the choriocapillaris (stained with endoglin, Fig. 3a, thick arrows), which generally appears to co-localize with IBA1 (Fig. 3b, thin arrows) and could thus represent infiltrating cells. Here again, the DIC image seems to point out an expression by hematopoietic cells adjacent to the RPE rather than by RPE cells.

MHC class II expression is found on most cells infiltrating the vitreous (Fig. 3c). Major co-staining with IBA1 likely identifies those cells as macrophages, considering that no microglial cell is found in the vitreous.
MHC class II expression at the level of inflamed vessels

A dense network of $\mathrm{MHC}$ class $\mathrm{II}^{+} \mathrm{IBA} 1^{+}$double-positive cells is found around vasculitis lesions (Fig. 4a). However, at the perivascular level, it is particularly difficult to differentiate microglia from macrophages, since the latter infiltrate the retina mainly through inflamed vessels. Indeed, many round-shaped cells co-expressing MHC class II and IBA1 are associated with blood vessels from which they seem to be getting out into the retina (Figs. 1b and 4). We could not detect a clear co-staining of MHC class II with $\mathrm{CD}_{31}{ }^{+}$endothelial cells or $\mathrm{GFAP}^{+}$ glial cells in the diseased retina, suggesting that, in this model, even during uveitis, endothelial and glial cells mostly do not express MHC class II (Fig. 4b). As shown more precisely in Fig. 1b, MHC class II expression seems to follow a "trans-retinal" pattern, high expression of MHC class II around inflamed retinal vessels being often found at the same level as MHC class II expression in outer retinal layers and on inflammatory cells infiltrating the vitreous.

\section{Quantification and phenotyping of retinal cells expressing MHC class II}

During inflammation, massive recruitment of inflammatory cells renders difficult the interpretation of IF images, especially around blood vessels. To further precise the nature and number of MHC class II-expressing cells, retinal single-cell suspensions were characterized by FC. Data from Fig. 5 show that the number of MHC class $\mathrm{II}^{+}$cells is very discriminative between healthy and EAU mice ( $p$ value $<0.001$ ). Moreover, a significantly higher number of MHC class $\mathrm{II}^{+}$cells is found in high-grade (grade $\geq 2$ ) uveitis compared to low-grade (grade $<2$ ) uveitis (Fig. 5a) ( $p$ value $<0.01$ ). Indeed, as illustrated by representative mice, we observed around $0.4 \% \mathrm{MHC}$ class II-expressing cells in the healthy retina (Fig. 5c), $1.8 \%$ in EAU grade 1 eyes (Fig. $5 \mathrm{~d}$ ), and up to $10 \%$ in grade 4 eyes (Fig. 5 e).

\section{Co-stimulatory molecule expression is induced on some MHC class II' cells during EAU}

To assess their potential as effective APCs, we next investigated whether retinal $\mathrm{MHC}$ class $\mathrm{II}^{+}$cells also express co-stimulatory molecules such as classically CD80, CD86, 
and CD40 during EAU. Naive retinas were used as control. During EAU, MHC class $\mathrm{II}^{+}$cells (Fig. 6a, red gate) display upregulated expression of CD80, CD86, and CD40 (Fig. 6b), compared to healthy retinal cells (Fig. 6d). Interestingly, a significantly higher proportion of $\mathrm{MHC}$ class II ${ }^{\text {hi }}$ cells (Fig. 6a, blue gate) compared to MHC class $\mathrm{II}^{+}$cells express co-stimulatory molecules during EAU (Fig. 6c, e). Kinetics of co-stimulatory molecule expression by $\mathrm{MHC}$ class $\mathrm{II}^{+}$cells during classical EAU and AT EAU are illustrated in Additional file 5: Figure S5.
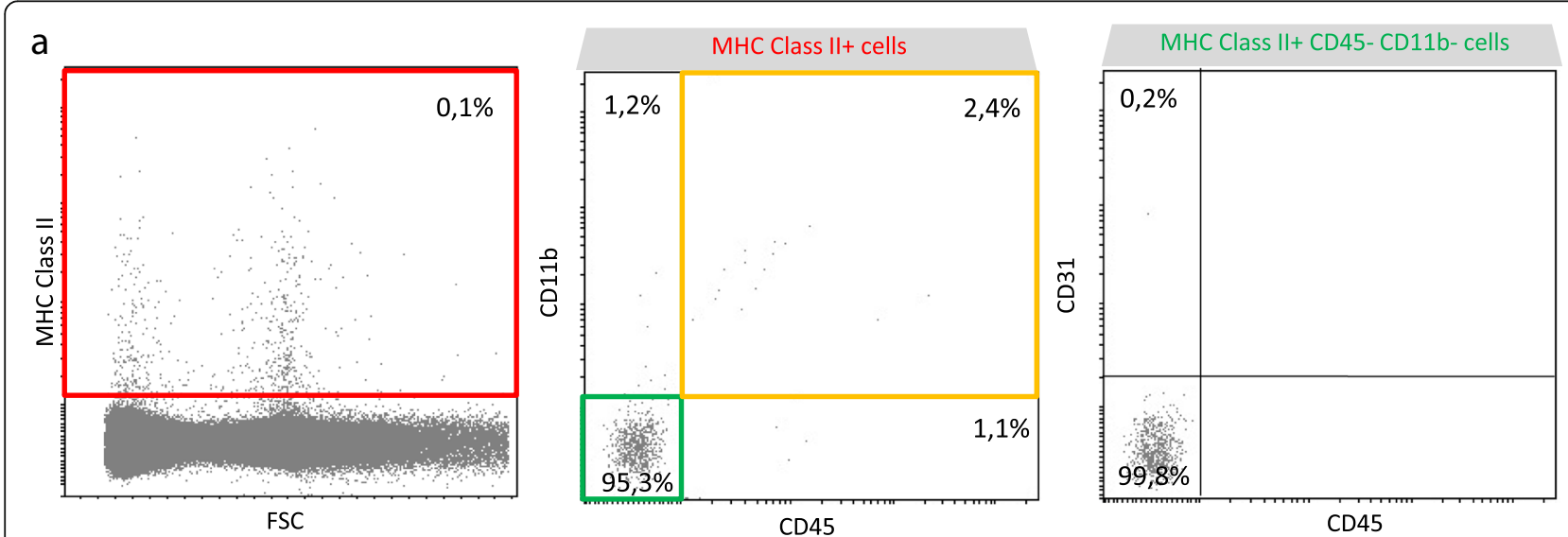

b

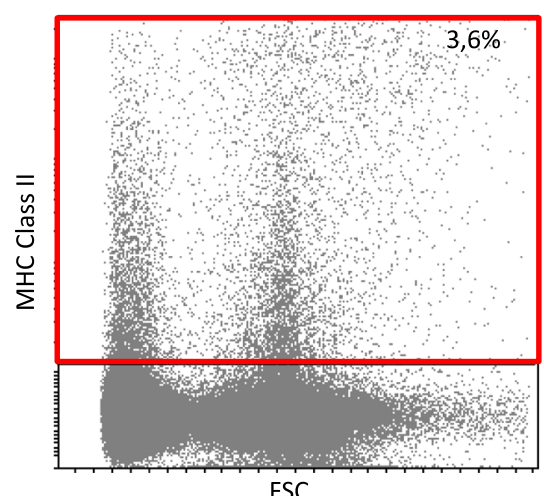

FSC

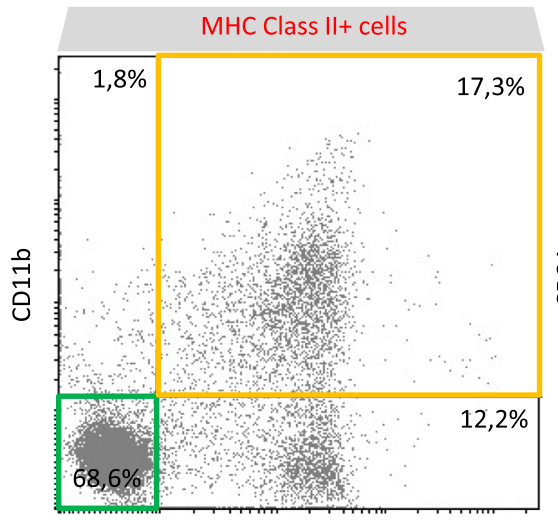

CD45
CD45

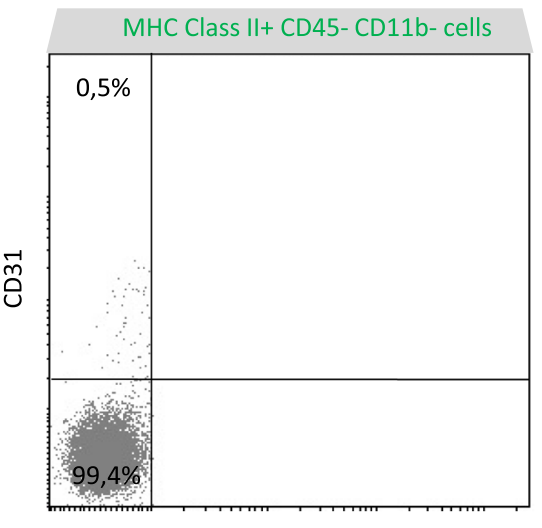

CD45

C

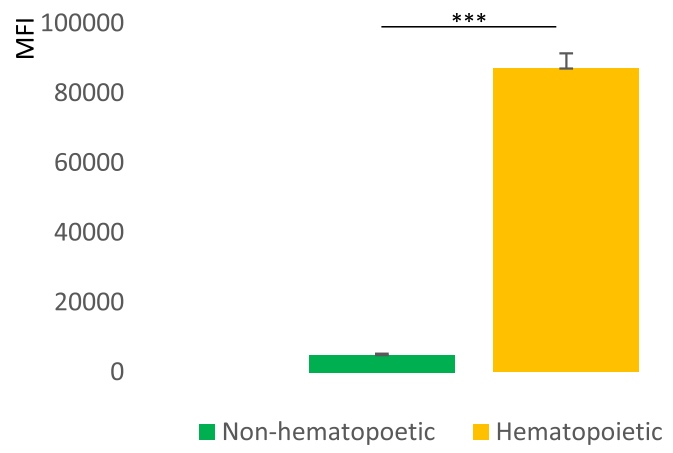

Fig. 7 During EAU, both hematopoietic and non-hematopoietic but mostly not endothelial cells are susceptible to express MHC class II. Three weeks after adoptive transfer, the retinas were carefully dissected, cut into small pieces, and dissociated by enzymatic digestion. Naive eyes were used as control. The single-cell suspensions, excluding dead cells (DAPI+) were analyzed by flow cytometry for MHC class II, CD45, CD11b, and CD31 expression using fluorochrome-conjugated-specific antibodies. Data are from one representative mouse out of three independent experiments involving four naive and eight EAU-independent animals. a Naive retina. Left: total retinal cells. Middle: gated on MHC class $\|^{+}$cells (red gate). Right: gated on non-hematopoietic MHC class $\|^{+} \mathrm{CD} 45^{-} \mathrm{CD} 11 \mathrm{~b}^{-}$cells (green gate). b Adoptive transfer uveitis (clinical grade 3.75). Left: total retinal cells. Middle: gated on MHC class $\|^{+}$cells (red gate). Right: gated on non-hematopoietic MHC class $\|^{+} \mathrm{CD}_{4} 5^{-} \mathrm{CD}_{1} 1 \mathrm{~b}^{-}$cells (green gate). c Histogram representation of the mean fluorescence intensity (MFI) for MHC class II expression by $C D 45^{+} C D 11 b^{+}$hematopoietic cells (orange gate) and CD45 ${ }^{-}$CD $11 b^{-}$non-hematopoietic cells (green gate) during EAU. Mean \pm SEM, Student's $t$ test, ${ }^{* *} p<0.001$ 


\section{Phenotypic characterization of MHC class II-expressing cells during $E A U$}

In naive retina, the few cells that express MHC class II are at $95 \% \mathrm{CD}_{4} 5^{-} \mathrm{CD} 11 \mathrm{~b}^{-}$non-hematopoietic cells (Fig. 7a, green gate). Among those $\mathrm{MHC}$ class $\mathrm{II}^{+}$nonhematopoietic cells, only $0.2 \%$ express CD31 (Fig. 7a). As shown in Fig. 7b, uveitis development is associated with a clear increase in $\mathrm{MHC}$ class $\mathrm{II}^{+}$hematopoietic cells co-expressing CD45 and CD11b (orange gate). However, there is almost no change in the percentage of $\mathrm{MHC}$ class $\mathrm{II}^{+}$non-hematopoietic cells that express CD31, confirming that endothelial cells mostly do not express MHC class II in this model of EAU. Interestingly, even during EAU, a large proportion of MHC class $\mathrm{II}^{+}$cells are non-hematopoietic, but as shown in Fig. 7c, their level of MHC class II expression is much lower than in hematopoietic cells.
To get further insight into the nature of $\mathrm{MHC}$ class $\mathrm{II}^{+}$ hematopoietic cells, we investigated the expression of the Ly6C marker, suspected to be expressed by infiltrating macrophages and not by resident microglia [17]. Figure 8a shows that in naive retina, the few $\mathrm{MHC}$ class $\mathrm{II}^{+}$ hematopoietic cells (orange gate) are mainly $\mathrm{Ly}_{6 \mathrm{C}}{ }^{-}$. During uveitis, the high increase in MHC class $\mathrm{II}^{+}$ hematopoietic cells leads to almost equal proportions of Ly6C $\mathrm{C}^{+}$and Ly6C $\mathrm{C}^{-}$cells (Fig. 8b).

$\mathrm{FC}$ analysis of $\mathrm{MHC}$ class $\mathrm{II}^{+}$cells in the retina was also performed in the two disease models at different timepoints (Additional file 6: Figure S6). When matched for disease grade, no significant difference was evidenced between different models and timepoints as concerns \% of cells expressing MHC class II, \% of hematopoietic cells among MHC class $\mathrm{II}^{+}$cells, MFI for MHC class II expression among hematopoietic or non-hematopoietic

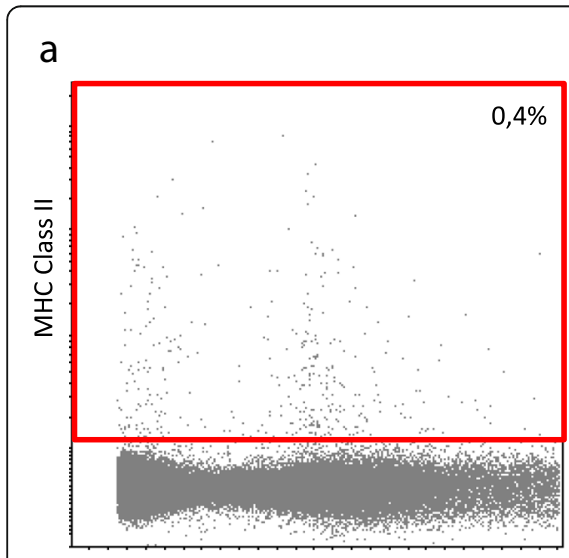

FSC

b

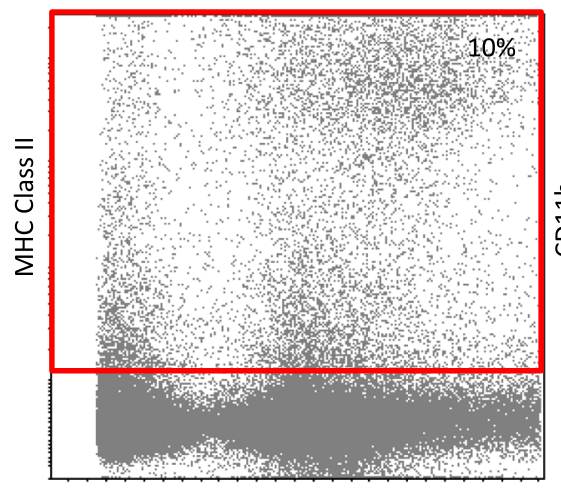

FSC

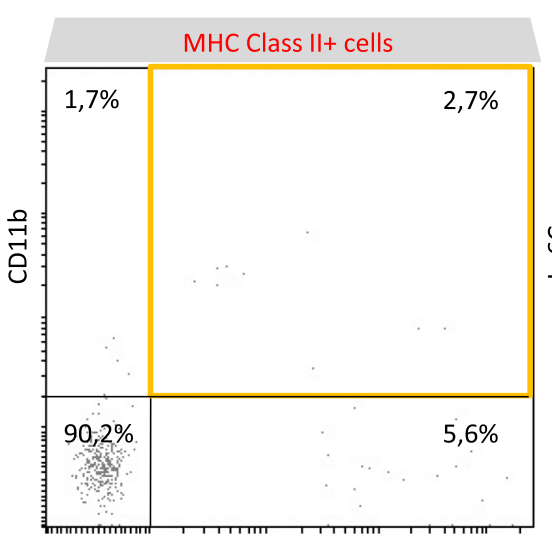

CD45

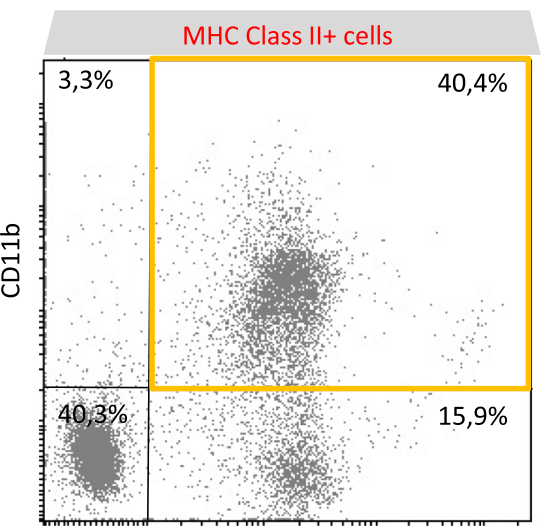

CD45

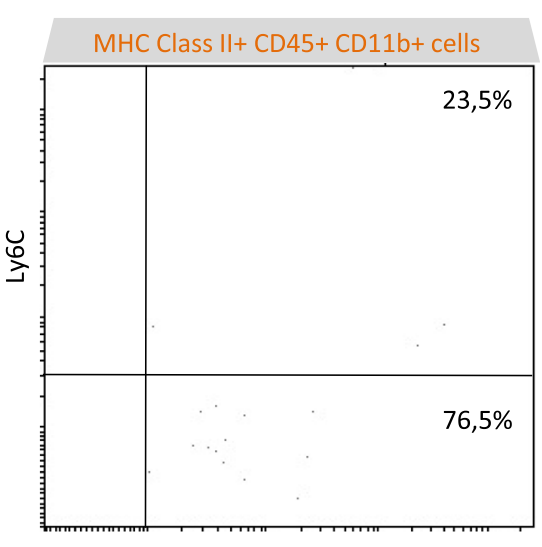

CD45

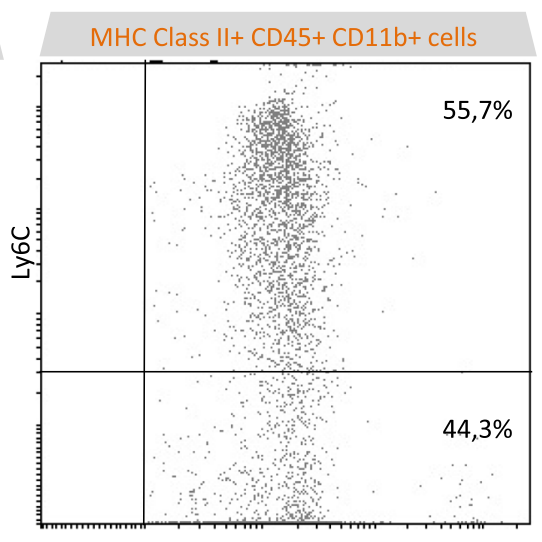

CD45

Fig. 8 During EAU, retinal hematopoietic MHC class II+ cells comprise both $\mathrm{Ly} 6 \mathrm{C}^{+}$and $\mathrm{Ly} 6 \mathrm{C}^{-}$cells. Three weeks after adoptive transfer, retinas were carefully dissected, cut into small pieces, and dissociated by enzymatic digestion. Naive eyes were used as control. The single-cell suspensions, excluding dead cells (DAPI+) were analyzed by flow cytometry for MHC class II, CD45, CD1 1b, and Ly6C expression using fluorochrome-conjugatedspecific antibodies. Data are from one representative mouse out of five independent experiments involving 7 naive and 12 EAU-independent animals. a Naive retina. Left: total retinal cells. Middle: gated on MHC class II $^{+}$cells (red gate). Right: gated on hematopoietic MHC class $\mathrm{II}^{+} \mathrm{CD} 45^{+} \mathrm{CD} 11 \mathrm{~b}^{+}$ cells (orange gate). b Adoptive transfer uveitis (clinical grade 4). Left: total retinal cells. Middle: gated on MHC class II ${ }^{+}$cells (red gate). Right: gated on hematopoietic MHC class $\mathrm{I}^{+} \mathrm{CD} 45^{+} \mathrm{CD} 11 \mathrm{~b}^{+}$cells (orange gate) 
MHC class $\mathrm{II}^{+}$cells, and \% of $\mathrm{Ly}^{+} \mathrm{C}^{+}$cells among hematopoietic MHC class $\mathrm{II}^{+}$cells (all $p$ values $>0.05$ ).

\section{Purification and RNA-Seq analysis of different MHC class II-expressing retinal cell populations}

We next wanted to dissect the role in $\mathrm{Ag}$ presentation of those Ly6C $\mathrm{C}^{-}$(resident?) and Ly6C $\mathrm{C}^{+}$(infiltrating?) cells during EAU. Unfortunately, the number of cells in each subpopulation of $\mathrm{MHC}$ class $\mathrm{II}^{+}$cells in the retina was far too low for in vitro functional testing of lymphocyte activation and proliferation. We thus used RNA-Seq analysis to compare the gene expression of separately sorted MHC class $\mathrm{II}^{+}$hematopoietic cells, further divided into $\mathrm{Ly}_{6 \mathrm{C}} \mathrm{C}^{+}$cells (referred to as Plus) and $\mathrm{Ly} 6 \mathrm{C}^{-}$ cells (referred to as Minus) and MHC class $\mathrm{II}^{+}$nonhematopoietic cells that expressed neither CD45/CD11b nor Ly6C (referred to as non-hematopoietic or $N H$ ) (three independent experiments, three mice pooled to generate each sample).

Figure 9a confirms that the sorting strategy was very effective as all markers used for cell sorting are correctly expressed at the mRNA level. We next generated a heatmap displaying the level of expression of the 30 most variant transcripts among all 9 samples. Blind bioinformatics analysis successfully leads to a clear clustering of all samples into three distinct populations, with major differences being found between Plus or Minus cells on the one side and NH cells on the other side (Fig. 9b). In addition, a similar procedure restricted to the six hematopoietic cell samples still allows a clear clustering of Plus and Minus cell populations (Fig. 9c).

Next, in order to explore whether Ly6C expression or non-expression allows distinction of macrophages from microglia, markers specific for macrophages $[18,19]$ or microglia [20] were selected from the literature. Figure 10a, b illustrates heatmaps displaying the relative mRNA levels of those genes in our samples. A relative but significant enrichment in macrophage markers is observed in the Plus population and conversely for microglial markers in the Minus population. However, some macrophage cell markers are also expressed by Minus cells and some microglial cell markers are expressed by Plus cells. a
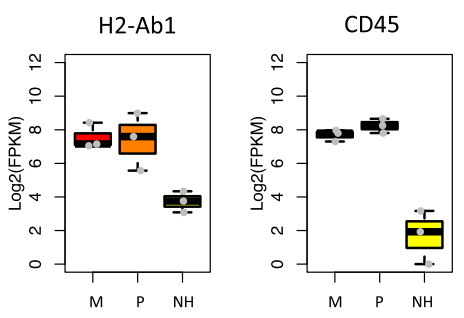

b

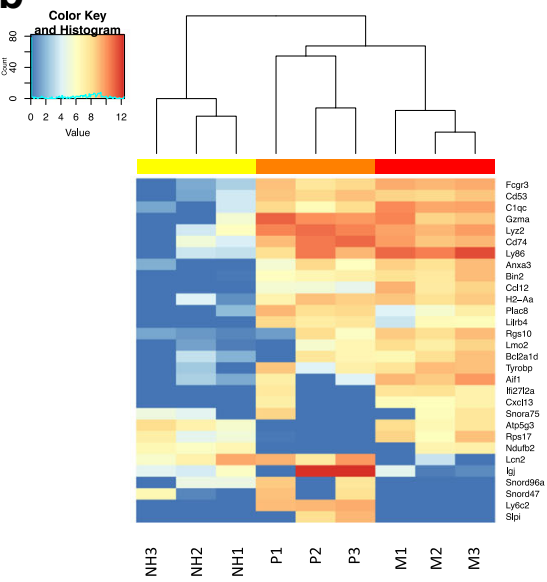

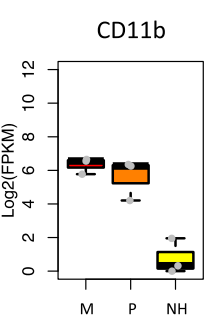

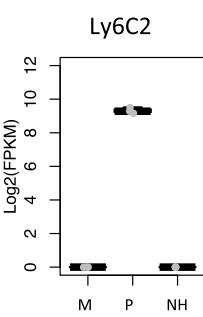

C

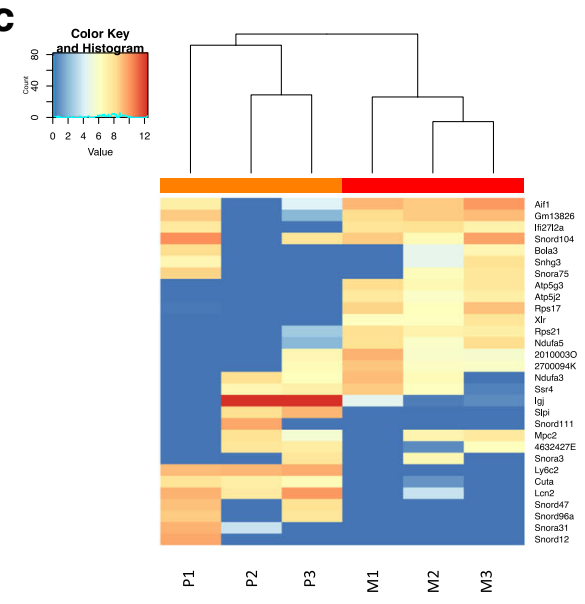

Fig. 9 Transcriptome analysis confirms the existence of different retinal cell populations expressing MHC class II during EAU. Three weeks after adoptive transfer, retinal single-cell suspensions were analyzed by flow cytometry and sorted into three different cell populations: MHC class II ${ }^{+} \mathrm{CD} 45^{+} \mathrm{CD} 11 \mathrm{~b}^{+} \mathrm{Ly}_{6 \mathrm{C}^{+}}$(Plus or P), MHC class II ${ }^{+} \mathrm{CD} 45^{+} \mathrm{CD} 11 \mathrm{~b}^{+}$Ly6C $\mathrm{C}^{-}$(Minus or M), and MHC class $\mathrm{II}^{+} \mathrm{CD} 45^{-} \mathrm{CD} 11 \mathrm{~b}^{-}$Ly6C $\mathrm{C}^{-}$cells (Non-hematopoietic or $\mathrm{NH}$ ). Each sample corresponds to a pool of three mice. a Cell population-dependent expression of the markers used for cell sorting. Data represented: boxplot of normalized mRNA expression levels (presented as Log 2 FPKM). $\mathbf{b}$ Heatmap and blind clustering analysis displaying the gene expression profiles for the 30 genes with the highest variance among all samples. Each row represents an individual gene and each column a sample. c Heatmap and blind clustering analysis displaying the gene expression profiles for the 30 genes with the highest variance among Plus and Minus samples. Each row represents an individual gene and each column a sample 

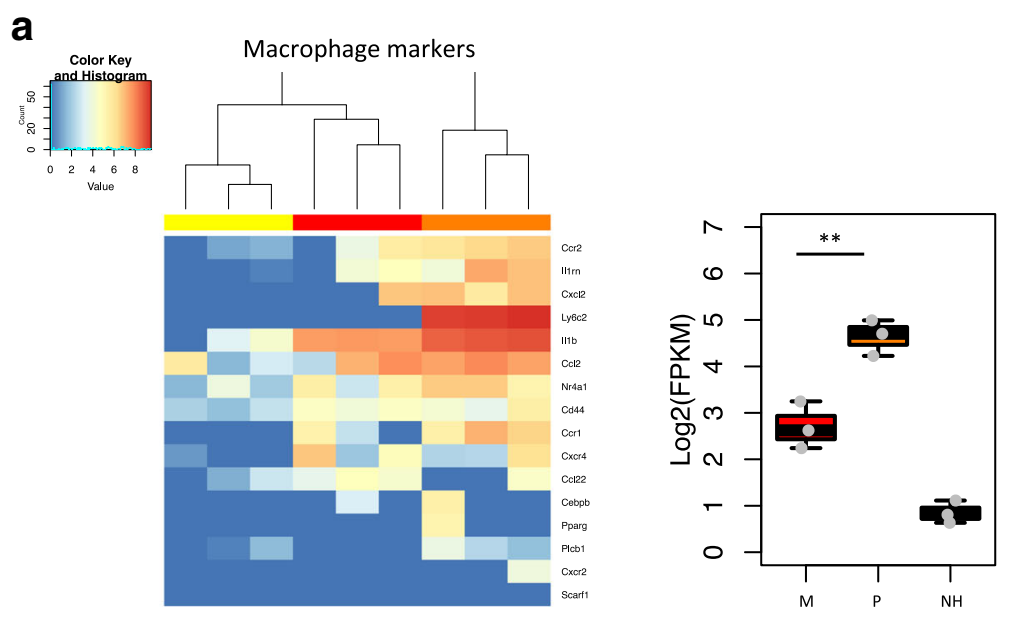

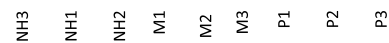

b
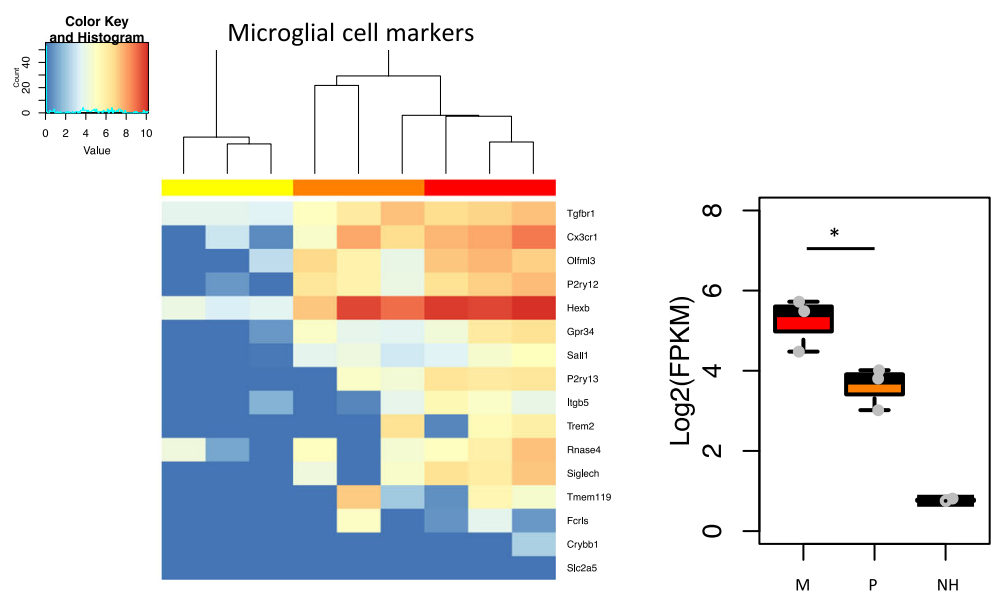

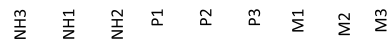

Fig. 10 Plus cells are enriched in macrophage makers while Minus cells preferentially express microglial cell markers. Three weeks after adoptive transfer, retinal single-cell suspensions were analyzed by flow cytometry and sorted into three different cell populations: MHC class $\|^{+} \mathrm{CD} 45$ ${ }^{+} \mathrm{CD} 11 \mathrm{~b}^{+} \mathrm{Ly} 6 \mathrm{C}^{+}$(Plus or P), MHC class $\|^{+} \mathrm{CD} 45^{+} \mathrm{CD} 11 \mathrm{~b}^{+} \mathrm{Ly} 6 \mathrm{C}^{-}$(Minus or M), and MHC class $\mathrm{I}^{+} \mathrm{CD} 45^{-} \mathrm{CD} 11 \mathrm{~b}^{-}$Ly6C $\mathrm{C}^{-}$cells (Non-hematopoietic or NH). a Left: heatmap displaying the gene expression profiles for genes known to be expressed by macrophages. Blind clustering analysis leads to clear separation of the nine samples into three cell populations. Right: boxplot representation of the mean expression of macrophage markers by each cell population. b Left: heatmap displaying the gene expression profiles for genes known to be expressed by microglia. Blind clustering analysis leads to clear separation of the nine samples into three cell populations. Right: boxplot representation of the mean expression of microglial cell markers by each cell population. Each row represents an individual gene and each column a sample from a pool of three mice. Statistical analysis was performed using $t$ tests, ${ }^{*} p$ value $<0.05,{ }^{* *} p$ value $<0.01$

Direct transcriptome comparison between Plus and Minus cells reveals 17 genes significantly modulated between the 2 cell populations (FDR $\leq 0.05)$ (Table 1 ). Tables 2 and 3 show the 30 most significantly regulated genes between Plus and $\mathrm{NH}$ and between Minus and NH cells, respectively.

The expression of three representative genes were validated at the protein level by FC. According to RNASeq data, Lcn2 expression is higher in Plus than that in Minus cells (Table 1). Cysltr1, conversely, is downregulated in Plus compared to Minus cells (Table 1). Finally, F4/80 is upregulated in Plus and Minus cells compared to NH cells (Tables 2 and 3). The percentage of cells expressing each gene product and respective MFI among the three different cell populations are illustrated in Fig. 11. Although involving small numbers of cells, data were highly reproducible among the six independent animals analyzed in two separate experiments.

Finally, functional analysis with the David web-based tool reveals that both hematopoietic cell populations 
Table 1 Gene signature of MHC class II $^{+}$Plus versus Minus cells

\begin{tabular}{|c|c|c|c|}
\hline Gene symbol & Gene name & $\log _{2} F C(P / M)$ & FDR \\
\hline Igj & Immunoglobulin joining chain & 8.6779562 & $2.29 \mathrm{E}-11$ \\
\hline Ly6c2 & Lymphocyte antigen 6 complex, locus C2 & 12.30121239 & 2.92E-09 \\
\hline Slfn4 & Schlafen 4 & 15.5668286 & $1.75 \mathrm{E}-06$ \\
\hline Len2 & Lipocalin 2 & 7.312076677 & 3.37E-05 \\
\hline Slpi & Secretory leukocyte peptidase inhibitor & 12.73813718 & 5.33E-05 \\
\hline Ccdc126 & Coiled-coil domain containing 126 & -8.341365207 & 0.000225043 \\
\hline Atp5g3 & ATP synthase, H+ transporting, mitochondrial F0 complex, subunit C3 (subunit 9) & -11.69540624 & 0.000280756 \\
\hline Fsd11 & Fibronectin type III and SPRY domain containing 1-like & -6.703008314 & 0.000462131 \\
\hline Dnajc12 & DnaJ heat shock protein family & -14.11777559 & 0.000618267 \\
\hline Rbm8a & RNA binding motif protein 8a & -11.28615955 & 0.001526552 \\
\hline Fat3 & FAT atypical cadherin 3 & -14.08641235 & 0.003575335 \\
\hline Col3a1 & Collagen, type III, alpha 1 & 14.61654737 & 0.003584831 \\
\hline Akap17b & A kinase (PRKA) anchor protein 17B & -10.53057236 & 0.009607167 \\
\hline Cysltr1 & Cysteinyl leukotriene receptor 1 & -14.65367542 & 0.009752316 \\
\hline Sgip1 & SH3-domain GRB2-like (endophilin) interacting protein 1 & -6.380242524 & 0.011651515 \\
\hline Pou2af1 & POU domain, class 2, associating factor 1 & 9.055182034 & 0.019402858 \\
\hline Dnm1 & Dynamin 1 & -12.9307709 & 0.050431759 \\
\hline
\end{tabular}

play a more important role in Ag processing and presentation in association with MHC class II and other pro-inflammatory functions than $N H$ cells (Table 4, FDR <0.05). No clear functional difference emerges between Plus and Minus cells (data not shown).

\section{Discussion}

EAU is a classical model of autoimmunity in which retinal Ag-specific $\mathrm{T}_{\mathrm{H}}$ cells drive the development of retinal inflammation. Local recognition of a retinal $\mathrm{Ag}$ is known to be required for $\mathrm{T}_{\mathrm{H}}$ cell reactivation and an important unresolved question is to determine which cells are responsible for in situ $\mathrm{MHC}$ class II expression and Ag presentation. The retina was long thought to be entirely devoid of MHC class II, as part of the immune privilege. However, in line with our data, some studies have highlighted faint MHC class II expression in the naive retina, as well as an increased expression of $\mathrm{MHC}$ class II during uveitis [21]. Despite years of research, great controversies remain on the role of MHC class II expression by different cell types in uveitis development. Our strategy to investigate this topic was to focus our studies on retinal MHC class II-expressing cells in a natural, non-transgenic, model of uveitis.

In this work, we demonstrate a strong upregulation, both in extent and intensity, of MHC class II expression in the retina during EAU. We also show that MHC class II induction significantly correlates with disease severity and is associated with higher co-stimulatory molecule expression, particularly on most MHC class II $^{\text {hi }}$ cells.
We further identify three $\mathrm{MHC}$ class $\mathrm{II}^{+}$retinal cell populations: $\mathrm{CD} 45^{-} \mathrm{CD} 11 \mathrm{~b}^{-}$cells of non-hematopoietic origin with low MHC class II expression and $\mathrm{CD} 45^{+} \mathrm{CD} 11 \mathrm{~b}^{+}$ cells of hematopoietic origin expressing higher levels of $\mathrm{MHC}$ class II, which can be further separated into Ly $6 \mathrm{C}^{+}$ and $\mathrm{Ly} 6 \mathrm{C}^{-}$cells. Transcriptome analysis of the three sorted populations leads to a clear sample clustering with some enrichment in macrophage markers and microglial cell markers in $\mathrm{Ly}_{6 \mathrm{C}} \mathrm{C}^{+}$and $\mathrm{Ly}_{6 \mathrm{C}}^{-}$cells, respectively. Finally, functional annotation analysis reveals no major functional differences between $\mathrm{Ly}_{6} \mathrm{C}^{+}$and $\mathrm{Ly}_{6 \mathrm{C}} \mathrm{C}^{-}$cells, both hematopoietic cell populations playing a more important role in Ag processing and presentation in association with MHC class II and in $\mathrm{T}$ cell activation than non-hematopoietic cells.

Our FC data provide evidence for a non-hematopoietic cell population that expresses $\mathrm{MHC}$ class II both in naïve neuro-sensory retina and during uveitis, although to a lower level than cells of hematopoietic origin. However, the nature of these cells could not be identified by IF. Indeed, we did not find strong MHC class II expression on astrocytes nor Müller cells. In agreement, Zhang et al. did not find MHC class II expression on astrocytes nor Müller cells during uveitis in an IFN- $\gamma$ induced model of ocular inflammation in rats [22]. In contrast, Jiang $\mathrm{G}$ et al. showed that retinal astrocytes express MHC class II during EAU in B10RIII mice [1]. Similarly, expression of MHC class II by RPE cells during uveitis was already described in both mice [23] and humans [24] more than 20 years ago. However, 
Table 2 Gene signature of MHC class II Plus versus Non-hematopoietic cells

\begin{tabular}{|c|c|c|c|}
\hline Gene symbol & Gene name & $\log _{2} \mathrm{FC}(\mathrm{P} / \mathrm{NH})$ & FDR \\
\hline Ly6c2 & Lymphocyte antigen 6 complex, locus C2 & 11.87357484 & $6.66 \mathrm{E}-09$ \\
\hline Rac2 & RAS-related C3 botulinum substrate 2 & 11.3730173 & $6.66 \mathrm{E}-09$ \\
\hline $\operatorname{lgj}$ & Immunoglobulin joining chain & 6.717543668 & $1.03 \mathrm{E}-07$ \\
\hline Ncr1 & Natural cytotoxicity triggering receptor 1 & 15.15445896 & $1.24 \mathrm{E}-07$ \\
\hline Clec5a & C-type lectin domain family 5 , member a & 14.40445716 & $1.29 \mathrm{E}-07$ \\
\hline Lilrb4 & Leukocyte immunoglobulin-like receptor, subfamily B, member $4 \mathrm{~A}$ & 11.01126519 & $3.08 \mathrm{E}-07$ \\
\hline Fli1 & Friend leukemia integration 1 & 11.46778052 & $3.13 \mathrm{E}-07$ \\
\hline Ly86 & Lymphocyte antigen 86 & 6.798033679 & $3.68 \mathrm{E}-07$ \\
\hline Gzma & Granzyme A & 6.705242775 & 2.05E-06 \\
\hline Ctss & Cathepsin S & 5.568780709 & $2.10 \mathrm{E}-06$ \\
\hline$\| 18 r 1$ & Interleukin 18 receptor 1 & 12.72237638 & $2.10 \mathrm{E}-06$ \\
\hline Gimap6 & GTPase, IMAP family member 6 & 15.15864883 & $2.10 \mathrm{E}-06$ \\
\hline Ctla4 & Cytotoxic T-lymphocyte-associated protein 4 & 14.67103293 & $2.31 \mathrm{E}-06$ \\
\hline Bin2 & Bridging integrator 2 & 7.565458144 & $2.31 \mathrm{E}-06$ \\
\hline $\mathrm{Cd} 74$ & CD74 antigen (invariant polypeptide of MHC, class II antigen-associated) & 6.334079696 & $2.59 \mathrm{E}-06$ \\
\hline Ccdc126 & Coiled-coil domain containing 126 & -9.776447913 & $2.62 \mathrm{E}-06$ \\
\hline Fcgr3 & Fc receptor, IgG, low affinity III & 6.739932279 & $2.62 \mathrm{E}-06$ \\
\hline Cd53 & CD53 antigen & 6.362290092 & $2.80 \mathrm{E}-06$ \\
\hline CD45 & Protein tyrosine phosphatase, receptor type, C & 6.186653535 & $2.91 \mathrm{E}-06$ \\
\hline Fsd11 & Fibronectin type III and SPRY domain containing 1-like & -8.081824945 & $2.91 \mathrm{E}-06$ \\
\hline $\mathrm{F} 4 / 80$ & Adhesion G protein-coupled receptor E1 & 8.087894562 & $2.91 \mathrm{E}-06$ \\
\hline Psd4 & Pleckstrin and Sec7 domain containing 4 & 14.6851914 & $2.91 \mathrm{E}-06$ \\
\hline Arhgdib & Rho, GDP dissociation inhibitor (GDI) beta & 6.696195491 & $2.91 \mathrm{E}-06$ \\
\hline Bank1 & B cell scaffold protein with ankyrin repeats 1 & 15.15703742 & $4.08 \mathrm{E}-06$ \\
\hline Pou2af1 & POU domain, class 2, associating factor 1 & 15.22372718 & 4.65E-06 \\
\hline Fyb & FYN binding protein & 6.232404471 & $6.35 \mathrm{E}-06$ \\
\hline Vsir & V-set immunoregulatory receptor & 8.022010319 & $6.95 \mathrm{E}-06$ \\
\hline Slpi & Secretory leukocyte peptidase inhibitor & 12.58889492 & $8.50 \mathrm{E}-06$ \\
\hline Lyz2 & Lysozyme 2 & 5.875787951 & $9.14 \mathrm{E}-06$ \\
\hline Anxa3 & Annexin $\mathrm{A} 3$ & 6.959651951 & $9.14 \mathrm{E}-06$ \\
\hline
\end{tabular}

although our IF data show some MHC class II expression at the level of the RPE, both contrast phase images and co-staining with IBA1 seem to indicate that this expression is attributable to infiltrating hematopoietic cells. Such MHC class II expression by IBA1 ${ }^{+}$subretinal cells has actually been described in $\mathrm{rd} 8$ mutant mice [25]. As concerns MHC class II expression by endothelial cells, neither immunostainings nor FC data demonstrate a clear expression. Surprisingly, both the presence $[4,26]$ and absence $[11,22]$ of MHC class II expression on endothelial cells have been described in the literature. This controversy can partially be explained by the use of different models and techniques. To further investigate this point, we also performed MHC class II staining on retinal wholemounts, confirming the presence of MHC class $\mathrm{II}^{+}$cells around retinal vessels, mostly in the shape of dendriform cells ensheathing the vessel (Additional file 7: Figure S7). This is in agreement with the work of Xu et al., who observed no expression of MHC class II by vascular endothelial cells in EAU retinal wholemounts [27]. Our data thus somehow question the fact that endothelial cells play a prominent role in $\mathrm{Ag}$ presentation to $T_{H}$ cells during EAU, even though those cells are the central element of the inner BRB and probably the first inner retinal cells encountered by autoreactive lymphocytes.

Recent and quite provocative data suggest that even neuronal cell types are capable of both constitutive and inducible MHC class II expression. Tonade et al. have 
Table 3 Gene signature of MHC class $\|^{+}$Minus versus Non-hematopoietic cells

\begin{tabular}{|c|c|c|c|}
\hline Gene aymbol & Gene name & $\log _{2} \mathrm{FC}(\mathrm{M} / \mathrm{NH})$ & FDR \\
\hline Ly86 & Lymphocyte antigen 86 & 8.243860053 & $5.61 \mathrm{E}-09$ \\
\hline Ctss & Cathepsin S & 6.957996729 & 9.43E-09 \\
\hline Bin2 & Bridging integrator 2 & 9.235207039 & 2.73E-08 \\
\hline Rac2 & RAS-related C3 botulinum substrate 2 & 10.60734368 & 2.73E-08 \\
\hline Clec5a & C-type lectin domain family 5 , member a & 15.17887896 & 2.73E-08 \\
\hline $\mathrm{F} 4 / 80$ & Adhesion G protein-coupled receptor E1 & 9.972224185 & 3.90E-08 \\
\hline Fcgr3 & Fc receptor, IgG, low affinity III & 7.775892583 & 1.20E-07 \\
\hline Gatm & Glycine amidinotransferase (L-arginine:glycine amidinotransferase) & 8.65338182 & 2.18E-07 \\
\hline Anxa3 & Annexin A3 & 8.397158434 & 2.55E-07 \\
\hline Ner1 & Natural cytotoxicity triggering receptor 1 & 14.1982847 & 3.02E-07 \\
\hline $\mathrm{Clqc}$ & Complement component 1, q subcomponent, C chain & 7.38704385 & 4.49E-07 \\
\hline Fli1 & Friend leukemia integration 1 & 10.50996433 & 1.65E-06 \\
\hline $\mathrm{Ccl} 12$ & Chemokine (C-C motif) ligand 12 & 15.2104167 & 2.66E-06 \\
\hline Hexb & Hexosaminidase B & 6.279744813 & 2.88E-06 \\
\hline Fyb & FYN binding protein & 6.513964387 & 3.63E-06 \\
\hline $\mathrm{C} \times 3 \mathrm{cr} 1$ & Chemokine (C-X3-C motif) receptor 1 & 6.581332934 & 3.77E-06 \\
\hline Ctla4 & Cytotoxic T-lymphocyte-associated protein 4 & 14.1739945 & 4.06E-06 \\
\hline Cd53 & CD53 antigen & 6.217529713 & 5.05E-06 \\
\hline Fcgr1 & Fc receptor, IgG, high affinity I & 10.93059649 & 5.90E-06 \\
\hline $\mid \mathrm{BA} 1$ & Allograft inflammatory factor 1 & 7.685685163 & 7.39E-06 \\
\hline Kctd12 & Potassium channel tetramerisation domain containing 12 & 6.343559988 & 7.75E-06 \\
\hline Lmo2 & LIM domain only 2 & 7.844870456 & 8.06E-06 \\
\hline Lilrb4 & Leukocyte immunoglobulin-like receptor, subfamily B, member 4A & 9.104873913 & 8.23E-06 \\
\hline Psd4 & Pleckstrin and Sec7 domain containing 4 & 13.93584229 & $8.46 \mathrm{E}-06$ \\
\hline$\| 18 \mathrm{r} 1$ & Interleukin 18 receptor 1 & 11.54035827 & 8.91E-06 \\
\hline Mpeg1 & Macrophage expressed gene 1 & 5.934098653 & 9.09E-06 \\
\hline Csf1r & Colony stimulating factor 1 receptor & 6.563851162 & 1.14E-05 \\
\hline Itgb2 & Integrin beta 2 & 7.391669553 & 1.16E-05 \\
\hline Arhgdib & Rho, GDP dissociation inhibitor (GDI) beta & 6.250951528 & 1.23E-05 \\
\hline C1qb & Complement component 1, q subcomponent, beta polypeptide & 6.508090307 & 1.42E-05 \\
\hline
\end{tabular}

FDR false discovery rate

recently shown that photoreceptor cells produce inflammatory mediators that stimulate leukocytes during diabetic retinopathy [28]. Another argument in favor of the possible role of photoreceptors in retinal inflammation is that opsin-driven SOCS1 overexpression mitigates EAU development [29]. Vagaska et al. further demonstrated that MHC class II is expressed in a subpopulation of human neural stem cells and on neurons, at least in vitro [30]. Finally, Charles et al. have even observed MHC class II expression on retinal neurons such as photoreceptors, during toxoplasma infection [31]. Yet unvalidated data from our lab suggest that at least part of the $N H$ MHC class II $^{\text {dim }}$ cell population might be composed of photoreceptors. Rods represent $80 \%$ of retinal cells. Contamination of the transcriptome of different retinal cell types by photoreceptor genes has been described by different groups, even when using a highly stringent sorting method relying on transgenic mouse lines in which different retinal cells are marked with fluorescent proteins [32, 33]. This contamination thus represents a possible limitation of our study and further investigation of this point is clearly needed.

MHC class II expression in the absence of appropriate co-stimulatory signals has been associated with induction of $\mathrm{T}$ cell apoptosis or anergy [34]. Our FC quantitative analyses of retinal single-cell suspensions demonstrate that $\mathrm{MHC}$ class II induction during EAU is associated with upregulation of co-stimulatory molecule expression. Furthermore, almost all cells expressing high levels of MHC class II display co-stimulatory molecules, 


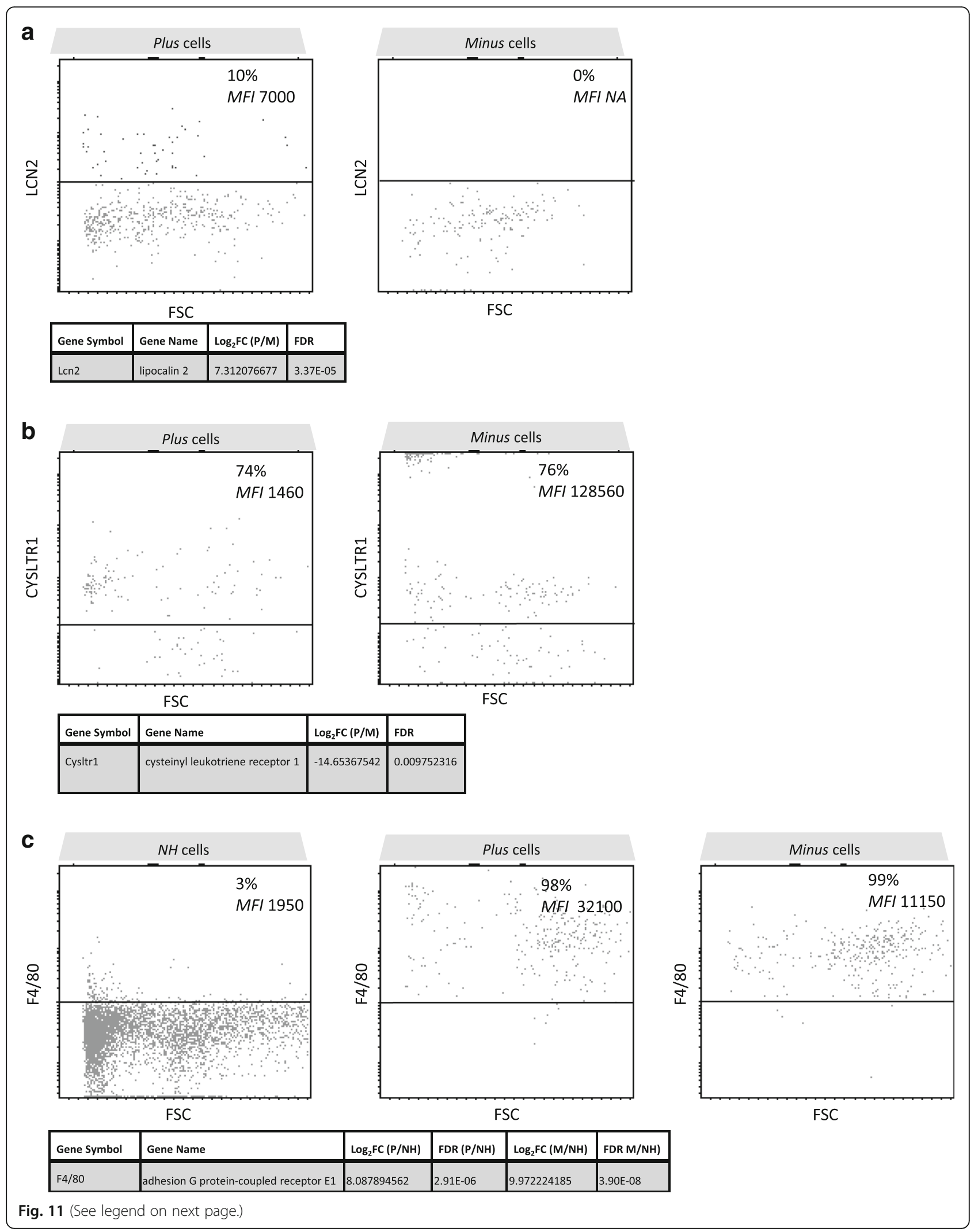


(See figure on previous page.)

Fig. 11 Validation of RNA-Seq data at the protein level. At day 21, after disease induction, the retinas were carefully dissected, cut into small pieces, and dissociated by enzymatic digestion. The single-cell suspensions, excluding dead cells (DAPI+) were analyzed by flow cytometry for MHC class II, CD45, CD11b, Ly6C, and either F4/80, LCN2, or Cysltr1 expression using fluorochrome-conjugated specific antibodies. Data are from one representative mouse out of two independent experiments involving six independent EAU animals. Data represented: percentage of cells expressing the marker and mean fluorescence intensity (MFI). Below dot plots, respective gene symbols, gene names, Log 2 FC and FDR for each marker are indicated. a Lcn2 differential expression by Plus and Minus cells. b Cysltr1 differential expression by Plus and Minus cells. c F4/80 differential expression by NH, Plus, and Minus cells

probably indicating higher APC potential. Unfortunately, due to the low absolute number of MHC class IIexpressing cells, we were not able to perform extensive phenotypic nor functional analyses of those costimulatory molecule-expressing cells. In the literature, data relative to in vivo retinal expression of costimulatory molecules are sparse. Tissue-resident cells with inducible MHC class II such as glia or vascular endothelium were reported to express CD80 and CD86 among other co-stimulatory signals under certain conditions and alter responses locally [35]. To our knowledge, only one study has described the expression of B7.1 (CD80) and B7.2 (CD86) in the eye at different timepoints during experimental autoimmune anterior uveitis, showing that both co-stimulatory molecules are expressed during the disease and downregulated with remission [36]. Besides, blockade of B7/CD28 [36] and disruption of CD40/CD40L interactions [37] were shown to inhibit EAU induction.

Within the retina, both resident and infiltrating cells have been reported to express MHC class II. In the normal retina, the only cells of hematopoietic origin were thought to be yolk sac-derived microglia. However, at least in the central nervous system, recent works also suggest the existence of perivascular macrophages of the same embryologic origin [38, 39]. During EAU, the retina is further invaded by infiltrating macrophages which express MHC class II [40]. Considering that MHC class II upregulation is also a hallmark of reactive microglia, the increase in $\mathrm{MHC}$ class $\mathrm{II}^{+} \mathrm{CD} 45^{+} \mathrm{CD} 11 \mathrm{~b}^{+}$cells can thus correspond either to the activation and replication of microglia or to invading macrophages. Moreover, although it has recently become clear that monocytederived macrophages recruited during inflammation and normal tissue-resident microglia have distinct developmental origins (bone marrow and yolk sac, respectively), a phenotypic overlap exists, with sharing of pan-macrophage markers such as IBA1 and CD11b. No research protocols allow perfect discrimination between those two cell types. Irradiation chimerism or parabiosis induces bias and/or technical limitations [19]. As concerns the transgenic $C C R 2^{\mathrm{rfp}}: \mathrm{Cx} 3 \mathrm{cr} 1^{\mathrm{gfp}}$, mouse model used to discriminate between CX3CR1GFP resident microglia and CCR2-RFP infiltrating monocyte-derived macrophages [41], not all monocytederived macrophages express CCR2 and they are also susceptible to express CX3CR1 [42]. Within the genetically unmodified mouse model of uveitis we used, some works have found that the level of CD45 expression defines $\mathrm{CD} 45^{\text {intermediate }}$ and $\mathrm{CD} 45^{\text {high }}$ populations, corresponding to microglia and recruited macrophages, respectively [43]. However, it has also been shown that activated microglia upregulate CD45 [44, 45] and that differentiation of monocytes into macrophages may be associated with downregulation of CD45 [46], sometimes to levels that make the two cell populations indistinguishable [47]. Accordingly, our FC data did not provide evidence for a clear $\mathrm{CD} 45^{\text {intermediate }}$ versus $\mathrm{CD} 45^{\text {high }}$ population among $\mathrm{MHC}$ class $\mathrm{II}^{+}$cells. Another option was to choose Ly6C expression to further discriminate microglia from macrophages among $\mathrm{MHC}$ class $\mathrm{II}^{+}$cells of hematopoietic origin. Indeed, several works showed that Ly6C is expressed mainly by infiltrating macrophages and not by microglia $[18,48]$. We thus isolated Ly6C-positive (Plus) and Ly6C-negative (Minus) cells among $\mathrm{MHC}$ class $\mathrm{II}^{+} \mathrm{CD} 45^{+} \mathrm{CD} 11 \mathrm{~b}^{+}$ hematopoietic cells and used transcriptome analysis to get insight into the nature and role of each cell type. Our bioinformatics analysis confirms to some extent the validity of Ly6C as a discriminative marker; although, some macrophage markers are expressed by Ly6C $\mathrm{C}^{-}$cells and some microglial cell markers are expressed by $\mathrm{Ly}_{6 \mathrm{C}}{ }^{+}$cells. Indeed, it is known that not all macrophages express Ly6C [49], and even that Ly6C

Table 4 Functional analysis of RNA-Seq data

\begin{tabular}{lll}
\hline $\log _{2} \mathrm{FC}(\mathrm{P} / \mathrm{NH})$ & $\mathrm{GO}$ terms & $\mathrm{Log} 2 \mathrm{FC}(\mathrm{M} / \mathrm{NH})$ \\
\hline 45.2 & Antigen processing and presentation of exogenous peptide antigen via MHC class II & 67.9 \\
12.4 & Positive regulation of T cell proliferation & 15.9 \\
12.0 & Phagocytose, engulfment & 15.5 \\
5.7 & Inflammatory response & 6.1 \\
\hline
\end{tabular}


expression is downregulated when monocytes migrate into tissues and differentiate into macrophages [46]. This could explain why macrophage markers are more significantly enriched in $\mathrm{Ly}_{6} \mathrm{C}^{+}$cells than microglial cell markers in $\mathrm{Ly}^{-} \mathrm{C}^{-}$cells, since the $\mathrm{Ly} 6 \mathrm{C}^{-}$population may contain Ly6 $\mathrm{C}^{-}$macrophages.

Only 17 genes were found to be significantly regulated between Plus and Minus cells, including Ly6C2. Among those differentially regulated genes, four are known inflammatory genes: Slfn4, Lcn2, Slpi, and Cysltr1. Three of those genes are upregulated in the Plus population: Slfn 4 is known to be upregulated during macrophage activation [50], while Lcn2 and Slpi are both upregulated in the experimental autoimmune encephalomyelitis (EAE) model [51, 52]. Lcn2 levels were even shown to be increased in the aqueous humor of patients with idiopathic acute anterior uveitis compared to controls [53]. Cysltr1 is upregulated in the Minus population and is known as a pro-inflammatory protein produced mainly by cells of the innate immune system including monocytes/macrophages [54]. Furthermore, two other significantly regulated genes, Sgip1 and Dnm1, are known for a role in the phagocytosis process. Besides, we found that Pou2af1, a gene still poorly described in the literature, is preferentially expressed by macrophages over microglia, in agreement with Gonzalez-Pena et al. [55].

Functional analysis reveals no major difference between Plus and Minus cells. Controversy exists regarding potential functional differences between microglia and macrophages in autoimmune diseases of the central nervous system. Wlodarczyk et al. demonstrated that, in the EAE model, a subpopulation of $\mathrm{CD} 11 \mathrm{c}^{+}$microglial cells are as effective as $\mathrm{CD} 11 \mathrm{c}^{+}$infiltrating cells in inducing proliferation of myelin oligodendrocyte glycoproteinimmunized $\mathrm{T}_{\mathrm{H}}$ cells [2]. Contrariwise, Yamasaki et al. highlighted many differences between the two cell types in the EAE model, macrophages being highly phagocytic and inflammatory whereas microglial cells had a globally suppressed metabolism [19]. As concerns EAU, Gregerson et al. demonstrated that $\mathrm{CD} 45^{+}$cells isolated from quiescent retina have little ability to present Ag, even when LPS-activated [56]. In our experimental settings, both Ly6C $\mathrm{C}^{+}$and Ly6C $\mathrm{C}^{-}$hematopoietic cell populations seem to play an important and comparable role in $\mathrm{Ag}$ presentation and $\mathrm{T}$ cell activation, when compared to non-hematopoietic cells.

\section{Conclusion}

Our results highlight the potential of cells of hematopoietic origin in local Ag presentation, whatever their Ly6C expression. Our work further provides a first transcriptomic study of MHC class II-expressing retinal cells during EAU and delivers a series of new candidate genes possibly implicated in the pathogenesis of retinal autoimmunity.

\section{Additional files}

Additional file 1: Figure S1. Complete gating strategy for flow cytometry experiments. Retinas were carefully dissected, cut into small pieces, and dissociated by incubation with Liberase DL and DNase I at $37^{\circ} \mathrm{C}$ for $45 \mathrm{~min}$. The single-cell suspensions were analyzed by flow cytometry. A. FSC versus SSC representation of the total cell population. The first gate was placed to exclude debris (P1). B. Within P1, Hoechst staining was used to exclude dead cells (P2). C. Within P2, doublets were excluded based on SSC (P3). D. Within P3, doublets were also excluded based on FSC (P4). All subsequent analyses were performed on cells gated in P4. (PPTX $106 \mathrm{~kb}$ )

Additional file 2: Figure S2. Purity of the sorted cell populations. Three weeks after adoptive transfer, retinal single-cell suspensions were analyzed by flow cytometry and sorted into three different cell populations, MHC class $I^{+} \mathrm{CD} 45^{+} \mathrm{CD} 11 \mathrm{~b}^{+} \mathrm{Ly}_{6 \mathrm{C}^{+}}$(Plus), $\mathrm{MHC}$ class $\mathrm{Il}^{+} \mathrm{CD} 45^{+} \mathrm{CD} 11 \mathrm{~b}^{+} \mathrm{Ly} \mathrm{C}^{-}$(Minus), and $\mathrm{MHC}$ class $\mathrm{I}^{+} \mathrm{CD} 45^{-} \mathrm{CD} 11 \mathrm{~b} \mathrm{~L}^{-} \mathrm{Ly}_{6 \mathrm{C}^{-}}(\mathrm{NH})$ cells. Each sample was sorted from a pool of three mice. Sorted cells were then re-analyzed by flow cytometry to assess the purity of cell sorting. Although hampered by very low cell numbers due to death or adherence to tube of many cells between the two analyses, this figure illustrates the purity among live MHC class $~^{+}{ }^{+}$cells. A. Sorted NH cells. B. Sorted Minus cells. C. Sorted Plus cells are too rare to allow reliable re-analysis (most re-analyzed Plus cells are found in the gate containing dead cells and debris). (PDF $354 \mathrm{~kb}$ )

Additional file 3: Figure S3. MHC class II retinal expression is highly induced during classical EAU and adoptive transfer EAU, both during induction and at disease peak. Eye cryosections were stained for MHC class II (green) and IBA1 (red) detection 21 days after classical EAU induction (B), 14 days (C) or 21 days after adoptive transfer (AT) (D). Naive eyes were used as control (A). In each picture, quantification was made with the co-staining module of the Imaris 7.3 software. Each cell was counted individually. Results are expressed as the percentage of $\mathrm{IBA}^{+}$or $\mathrm{MHCll}^{+}$single positive cells and $\mathrm{IBA} 1^{+} \mathrm{MHCl|}^{+}$double-positive cells among the total of single and double-positive cells. The DIC image was added to better localize the RPE. A. MHC class II expression in naïve eyes. B. MHC class II expression during classical EAU at day 21. C. MHC class II expression during AT EAU at day 14. D. MHC class II expression during AT EAU at day 21. (PPTX $3600 \mathrm{~kb}$ )

Additional file 4: Figure S4. MHC class II expression in the retina during classical EAU. Three weeks after immunization, eye cryosections were prepared and stained for MHC class II (green) and IBA1 (red) or endoglin (magenta) detection. Cell nuclei were stained with Hoechst (blue). Each picture was chosen as representative of an experiment conducted on six or more animals. A. MHC class II and IBA1 expression. B. MHC class II and endoglin expression. (PPTX $7276 \mathrm{~kb}$ )

Additional file 5: Figure S5. Kinetics of co-stimulatory molecule expression by MHC class $I I \pm$ cells during classical EAU and adoptive transfer EAU. Fourteen or 21 days after disease induction, the retinas were carefully dissected, cut into small pieces, and dissociated by enzymatic digestion. The single-cell suspensions, excluding dead cells (DAPI+), were analyzed by flow cytometry for MHC class II, CD80, CD86, and CD40 expression using fluorochrome-conjugated-specific antibodies. Data are representative of three independent animals for each disease model and timepoint, matched for disease grade. Only MHC class $\mathrm{II}^{+}$cells are shown. A. Classical EAU, day 14. B. Classical EAU, day 21. C. Adoptive transfer EAU, day 14. (PPTX 2433 kb)

Additional file 6: Figure S6. Kinetics of MHC class II and hematopoietic cell marker expression on the three types of potential APCs during classical EAU and adoptive transfer EAU. Fourteen or 21 days after disease induction, retinas were carefully dissected, cut into small pieces, and dissociated by enzymatic digestion. The single-cell suspensions, excluding dead cells $(\mathrm{DAPI}+)$, were analyzed by flow cytometry for MHC class II, CD45, CD11 b, and Ly6C expression using fluorochrome-conjugated specific antibodies. Data are representative of three independent animals for each disease model and timepoint, matched for disease grade. Data represented: Mean \pm SEM. For each histogram, groups were compared using KruskalWallis tests (all $p$ values $>0.05$ ). A. Percentage of $\mathrm{MHC}$ class $\mathrm{I}^{+}$cells in the retina during classical EAU or adoptive transfer (AT) EAU, at day 14 or day 21. B. Percentage of hematopoietic CD $45^{+} \mathrm{CD} 11 \mathrm{~b}^{+}$cells among $\mathrm{MHC}$ class $\mathrm{II}^{+}$cells in the retina during classical EAU or AT EAU, at day 
14 or day 21. C. MFI for MHC class II expression by hematopoietic or non-hematopoietic cells in the retina during classical EAU or AT EAU, at day 14 or day 21. D. Percentage of $\mathrm{Ly}_{6 \mathrm{C}}{ }^{+}$cells among hematopoietic $\mathrm{MHC}$ class $\mathrm{II}^{+}$cells in the retina during classical EAU or AT EAU, at day 14 or day 21. (PPTX $57 \mathrm{~kb}$ )

Additional file 7: Figure S7. Analysis of MHC class II expression in retinal wholemounts during adoptive transfer EAU. Three weeks after adoptive transfer, the eyes were collected and the whole retinas were dissected and stained for MHC class II (green) and endoglin (magenta) detection. Retinas from three independent animals were stained in one experiment. A. MHC class II and endoglin expression at the ora serrata. B. MHC class II and endoglin expression in the central retina. C. MHC class II and endoglin expression around the optic nerve. (PPTX $1345 \mathrm{~kb}$ )

\section{Abbreviations}

Ag: Antigen; APC: Antigen-presenting cell; AT: Adoptive transfer; BRB: Bloodretinal barrier; CB: Ciliary body; CD: Cluster differentiation; CD11 b: Itgam, integrin alpha $\mathrm{M} ; \mathrm{CD} 31$ : PECAM-1, Platelet endothelial cell adhesion molecule 1; CD45: ptprc, protein tyrosine phosphatase, receptor type, C; CFA: Freund's complete adjuvant; Cysltr1: Cysteinyl leukotriene receptor 1; DIC: Differential interference contrast; EAE: Experimental autoimmune encephalomyelitis; EAU: Experimental autoimmune uveitis; FACS: Fluorescence-activated cell sorting; FC: Flow cytometry; FDR: False discovery rate; FMO: Fluorescence minus one; FPKM: Fragments per kilobase of exon per million mapped reads; GFAP: Glial fibrillary acidic protein; IBA1: AIF1, allograft inflammatory factor 1; IF: Immunofluorescence; IRBP: Interphotoreceptor retinoid-binding protein; IRBP 1-20: IRBP peptide 1-20; LCn 2: Lipocalin 2; $\log _{2} F C$ : $\log _{2}$ fold change; Ly6C: Lymphocyte antigen 6 complex; MHC: Major histocompatibility complex; NH: Non-hematopoietic; ONL: Outer nuclear layer; OS: Ora serrata; PFA: Paraformaldehyde; PTX: Pertussis toxin; RPE: Retinal pigment epithelium; SD: Standard deviation; SEM: Standard error of the mean; TCR: T cell receptor; $T_{H}:$ T helper lymphocyte

\section{Acknowledgements}

The authors would like to thank Jean-Marie Vanderwinden for his microscopy and imaging guidance, Vincent Lambert and Julie Lecomte for their advice in retinal wholemount preparation, Christine Dubois for FACS sorting, Frederick Libert and Anne Lefort for their contribution to RNA sequencing, and Viviane De Maertelaer for statistical analysis.

\section{Funding}

This work was supported by Fonds Erasme, Association Vésale, FER (Fonds d'encouragement à la recherche) and the funds for research in ophthalmology (FRO, Ligue Braille).

\section{Availability of data and materials}

The datasets analyzed during the current study are available from the corresponding author on reasonable request.

\section{Authors' contributions}

$\mathrm{DL}, \mathrm{RD}, \mathrm{CB}$, and FW designed the research project. $\mathrm{DL}, \mathrm{RD}, \mathrm{VF}$, and $\mathrm{CB}$ performed the research, collected, and analyzed the data. MD performed RNA-Seq bioinformatics analysis. DL, CB, and FW wrote the manuscript. LC participated in critical reviewing of the manuscript. All authors read and approved the final manuscript.

\section{Authors' information}

Not applicable.

\section{Ethics approval}

Animals were housed at the animal facilities in accordance with the European guidelines. Animal treatment conformed to the ARVO Statement for the Use of Animals in Ophthalmic and Vision Research. Ethics approval (protocol 515N) was obtained from the Ethics Committee (Comission d'Ethique du Bien-Être Animal, CEBEA), and is valid through January 2018.

\section{Consent for publication}

Not applicable

\section{Competing interests}

The authors declare that they have no competing interests.

\section{Publisher's Note}

Springer Nature remains neutral with regard to jurisdictional claims in published maps and institutional affiliations.

\section{Author details}

'Ophthalmology Group, IRIBHM (Institut de Recherche Interdisciplinaire en Biologie Humaine et Moléculaire), Université Libre de Bruxelles (ULB), Erasme Campus, Building C, Room C6.117, 808 Route de Lennik, 1070 Brussels, Belgium. ${ }^{2}$ Ophthalmology Department of Erasme Hospital, Université Libre de Bruxelles (ULB), 808 Route de Lennik, 1070 Brussels, Belgium.

${ }^{3}$ Ophthalmology Department of CHU Saint-Pierre, 322 Rue Haute, 1000 Brussels, Belgium. ${ }^{4}$ Ophthalmology Department of CHU Brugmann, 4 Place Van Gehuchten, 1020 Brussels, Belgium. Interuniversity Institute of Bioinformatics in Brussels, Université Libre de Bruxelles - Vrije Universiteit Brussel, La Plaine Campus, BC building, 6th floor, CP 263, Triomflaan, 1050 Brussels, Belgium.

Received: 24 January 2017 Accepted: 11 July 2017

Published online: 18 July 2017

\section{References}

1. Jiang G, Ke Y, Sun D, Han G, Kaplan HJ, Shao H. Reactivation of uveitogenic $T$ cells by retinal astrocytes derived from experimental autoimmune uveitis-prone B10RIII mice. Invest Ophthalmol Vis Sci. 2008;49:282-9.

2. Wlodarczyk A, Løbner M, Cédile O, Owens T. Comparison of microglia and infiltrating $\mathrm{CD}_{11} \mathrm{c}^{+}$cells as antigen presenting cells for $\mathrm{T}$ cell proliferation and cytokine response. J Neuroinflammation. 2014;11:57.

3. Bottazzo GF, Pujol-Borrell R, Hanafusa T, Feldmann M. Role of aberrant HLA-DR expression and antigen presentation in induction of endocrine autoimmunity. Lancet Lond Engl. 1983;2:1115-9.

4. Lightman S. Immune mechanisms in autoimmune ocular disease. Eye Lond Engl. 1988;2(Pt 3):260-6

5. Caspi RR. A look at autoimmunity and inflammation in the eye. J Clin Invest. 2010;120:3073-83.

6. Willermain F, Rosenbaum JT, Bodaghi B, Rosenzweig HL, Childers S, Behrend T, et al. Interplay between innate and adaptive immunity in the development of non-infectious uveitis. Prog Retin Eye Res. 2012;31:182-94.

7. Dewispelaere R, Lipski D, Foucart V, Bruyns C, Frère A, Caspers L, et al. ICAM-1 and VCAM-1 are differentially expressed on blood-retinal barrier cells during experimental autoimmune uveitis. Exp Eye Res. 2015;137:94-102.

8. Prendergast RA, lliff CE, Coskuncan NM, Caspi RR, Sartani G, Tarrant TK, et al. $T$ cell traffic and the inflammatory response in experimental autoimmune uveoretinitis. Invest Ophthalmol Vis Sci. 1998:39:754-62.

9. Thurau SR, Mempel TR, Flügel A, Diedrichs-Möhring M, Krombach F, Kawakami $\mathrm{N}$, et al. The fate of autoreactive, GFP+ T cells in rat models of uveitis analyzed by intravital fluorescence microscopy and FACS. Int Immunol. 2004;16:1573-82.

10. Chan CC, Caspi RR, Roberge FG, Nussenblatt RB. Dynamics of experimental autoimmune uveoretinitis induced by adoptive transfer of S-antigen-specific T cell line. Invest Ophthalmol Vis Sci. 1988;29:411-8.

11. Ishimoto S, Zhang J, Gullapalli VK, Pararajasegaram G, Rao NA. Antigenpresenting cells in experimental autoimmune uveoretinitis. Exp Eye Res. 1998;67:539-48

12. Shao H, Liao T, Ke Y, Shi H, Kaplan HJ, Sun D. Severe chronic experimental autoimmune uveitis (EAU) of the C57BL/6 mouse induced by adoptive transfer of IRBP1-20-specific T cells. Exp Eye Res. 2006;82:323-31.

13. Xu H, Koch P, Chen M, Lau A, Reid DM, Forrester JV. A clinical grading system for retinal inflammation in the chronic model of experimental autoimmune uveoretinitis using digital fundus images. Exp Eye Res. 2008;87:319-26.

14. Tachikawa M, Toki H, Tomi M, Hosoya K. Gene expression profiles of ATP-binding cassette transporter $\mathrm{A}$ and $\mathrm{C}$ subfamilies in mouse retina vascular endothelial cells. Microvasc Res. 2008;75:68-72.

15. Liao Y, Smyth GK, Shi W. featureCounts: an efficient general purpose program for assigning sequence reads to genomic features. Bioinforma Oxf Engl. 2014;30:923-30

16. Dennis G, Sherman BT, Hosack DA, Yang J, Gao W, Lane HC, et al. DAVID: Database for Annotation, Visualization, and Integrated Discovery. Genome Biol. 2003;4:P3. 
17. Vainchtein ID, Vinet J, Brouwer N, Brendecke S, Biagini G, Biber K, et al. In acute experimental autoimmune encephalomyelitis, infiltrating macrophages are immune activated, whereas microglia remain immune suppressed. Glia. 2014:62:1724-35.

18. Lewis ND, Hill JD, Juchem KW, Stefanopoulos DE, Modis LK. RNA sequencing of microglia and monocyte-derived macrophages from mice with experimental autoimmune encephalomyelitis illustrates a changing phenotype with disease course. J Neuroimmunol. 2014;277:26-38

19. Yamasaki R, Lu H, Butovsky O, Ohno N, Rietsch AM, Cialic R, et al. Differential roles of microglia and monocytes in the inflamed central nervous system. J Exp Med. 2014;211:1533-49.

20. Butovsky O, Jedrychowski MP, Moore CS, Cialic R, Lanser AJ, Gabriely G, et al. Identification of a unique TGF- $\beta$-dependent molecular and functional signature in microglia. Nat Neurosci. 2014;17:131-43.

21. Calder VL, Lightman SL. Experimental autoimmune uveoretinitis (EAU) versus experimental allergic encephalomyelitis (EAE): a comparison of T cell-mediated mechanisms. Clin Exp Immunol. 1992:89:165-9.

22. Zhang J, Wu GS, Ishimoto S, Pararajasegaram G, Rao NA. Expression of major histocompatibility complex molecules in rodent retina. Immunohistochemica study. Invest Ophthalmol Vis Sci. 1997;38:1848-57.

23. Chan CC, Hooks JJ, Nussenblatt RB, Detrick B. Expression of la antigen on retinal pigment epithelium in experimental autoimmune uveoretinitis. Curr Eye Res. 1986:5:325-30.

24. Chan CC, Detrick B, Nussenblatt RB, Palestine AG, Fujikawa LS, Hooks JJ. HLA-DR antigens on retinal pigment epithelial cells from patients with uveitis. Arch Ophthalmol Chic III 1960. 1986;104:725-9.

25. Aredo B, Zhang K, Chen X, Wang CX-Z, Li T, Ufret-Vincenty RL. Differences in the distribution, phenotype and gene expression of subretinal microglia/ macrophages in C57BL/6 N (Crb1 rd8/rd8) versus C57BL6/J (Crb1 wt/wt) mice. J Neuroinflammation. 2015:12:6.

26. Fujikawa LS, Chan CC, MCAllister C, Gery I, Hooks JJ, Detrick B, et al. Retinal vascular endothelium expresses fibronectin and class II histocompatibility complex antigens in experimental autoimmune uveitis. Cell Immunol. 1987;106:139-50.

27. Xu H, Dawson R, Forrester JV, Liversidge J. Identification of novel dendritic cell populations in normal mouse retina. Invest Ophthalmol Vis Sci. 2007;48:1701-10.

28. Tonade D, Liu H, Kern TS. Photoreceptor cells produce inflammatory mediators that contribute to endothelial cell death in diabetes diabetes-induced inflammation in photoreceptors. Invest Ophthalmol Vis Sci. 2016;57:4264-71.

29. Yu C-R, Mahdi RR, Oh H-M, Amadi-Obi A, Levy-Clarke G, Burton J, et al, Suppressor of cytokine signaling-1 (SOCS1) inhibits lymphocyte recruitment into the retina and protects SOCS1 transgenic rats and mice from ocular inflammation. Invest Ophthalmol Vis Sci. 2011:52:6978-86.

30. Vagaska B, New SEP, Alvarez-Gonzalez C, D'Acquisto F, Gomez SG, Bulstrode NW, et al. MHC-class-II are expressed in a subpopulation of human neural stem cells in vitro in an IFNy-independent fashion and during development. Sci Rep. 2016;6:24251.

31. Charles E, Joshi S, Ash JD, Fox BA, Farris AD, Bzik DJ, et al. CD4 T-cell suppression by cells from Toxoplasma gondii-infected retinas is mediated by surface protein PD-L1. Infect Immun. 2010;78:3484-92.

32. Whitmore SS, Wagner AH, DeLuca AP, Drack AV, Stone EM, Tucker BA, et al. Transcriptomic analysis across nasal, temporal, and macular regions of human neural retina and RPE/choroid by RNA-Seq. Exp Eye Res. 2014;129:93-106.

33. Siegert S, Cabuy E, Scherf BG, Kohler H, Panda S, Le Y-Z, et al. Transcriptional code and disease map for adult retinal cell types. Nat Neurosci. 2012:15:487-95.

34. Shemer A, Jung S. Differential roles of resident microglia and infiltrating monocytes in murine CNS autoimmunity. Semin Immunopathol. 2015;37:613-23.

35. Gregerson DS, Kawashima H. APC derived from donor splenocytes support retinal autoimmune disease in allogeneic recipients. J Leukoc Biol. 2004:76:383-7.

36. Shao H, Sun D, Sun SL, Cruze JM, Bora N, Kaplan HJ. Expression of B7 molecules in the eye during experimental autoimmune anterior uveitis (EAAU). Curr Eye Res. 2002;25:271-7.

37. Bagenstose LM, Agarwal RK, Silver PB, Harlan DM, Hoffmann SC, Kampen RL, et al. Disruption of CD40/CD40-ligand interactions in a retinal autoimmunity model results in protection without tolerance. J Immunol Baltim Md 1950. 2005; 175:124-30.

38. Dick AD, Ford AL, Forrester JV, Sedgwick JD. Flow cytometric identification of a minority population of MHC class II positive cells in the normal rat retina distinct from CD45lowCD11b/c + CD4low parenchymal microglia. Br J Ophthalmol. 1995;79:834-40.
39. Greter M. Family ties among CNS macrophages. Nat Immunol. 2016;17:742-3.

40. Jiang HR, Lumsden L, Forrester JV. Macrophages and dendritic cells in IRBP-induced experimental autoimmune uveoretinitis in B10RIII mice. Invest Ophthalmol Vis Sci. 1999;40:3177-85.

41. Saederup N, Cardona AE, Croft K, Mizutani M, Cotleur AC, Tsou C-L, et al. Selective Chemokine Receptor Usage by Central Nervous System Myeloid Cells in CCR2-Red Fluorescent Protein Knock-In Mice. PLoS ONE. 2010;5. doi:10.1371/journal.pone.0013693.

42. London A, Benhar I, Mattapallil MJ, Mack M, Caspi RR, Schwartz M. Functional macrophage heterogeneity in a mouse model of autoimmune central nervous system pathology. J Immunol. 2013;190:3570-8.

43. Patel AR, Ritzel R, McCullough LD, Liu F. Microglia and ischemic stroke: a double-edged sword. Int J Physiol Pathophysiol Pharmacol. 2013:5:73-90.

44. Zhang GX, Li J, Ventura E, Rostami A. Parenchymal microglia of naïve adult C57BL/6 J mice express high levels of B7.1, B7.2, and MHC class II. Exp Mol Pathol. 2002;73:35-45.

45. Maneu V, Noailles A, Megías J, Gómez-Vicente V, Carpena N, Gil ML, et al. Retinal microglia are activated by systemic fungal infection. Invest Ophthalmol Vis Sci. 2014;55:3578-85.

46. O'Koren EG, Mathew R, Saban DR. Fate mapping reveals that microglia and recruited monocyte-derived macrophages are definitively distinguishable by phenotype in the retina. Sci Rep. 2016:6:20636

47. Müller A, Brandenburg S, Turkowski K, Müller S, Vajkoczy P. Resident microglia, and not peripheral macrophages, are the main source of brain tumor mononuclear cells. Int J Cancer J Int Cancer. 2015;137:278-88.

48. Chu CJ, Gardner PJ, Copland DA, Liyanage SE, Gonzalez-Cordero A, Kleine Holthaus S-M, et al. Multimodal analysis of ocular inflammation using endotoxin-induced uveitis. Dis Model Mech. 2016. doi:10.1242/dmm.022475.

49. Liyanage SE, Gardner PJ, Ribeiro J, Cristante E, Sampson RD, Luhmann UFO, et al. Flow cytometric analysis of inflammatory and resident myeloid populations in mouse ocular inflammatory models. Exp Eye Res. 2016;151:160-70.

50. van Zuylen WJ, Garceau V, Idris A, Schroder K, Irvine KM, Lattin JE, et al. Macrophage activation and differentiation signals regulate schlafen-4 gene expression: evidence for Schlafen-4 as a modulator of myelopoiesis. PLoS One. 2011. doi:10.1371/journal.pone.0015723.

51. Berard JL, Zarruk JG, Arbour N, Prat A, Yong WW, Jacques FH, et al. Lipocalin 2 is a novel immune mediator of experimental autoimmune encephalomyelitis pathogenesis and is modulated in multiple sclerosis. Glia. 2012;60:1145-59.

52. Müller AM, Jun E, Conlon H, Sadiq SA. Inhibition of SLPI ameliorates disease activity in experimental autoimmune encephalomyelitis. BMC Neurosci. 2012;13:30.

53. Salom D, Sanz-Marco E, Mullor JL, Lopez-Prats MJ, Garcia-Delpech S, Udaondo P, et al. Aqueous humor neutrophil gelatinase-associated lipocalin levels in patients with idiopathic acute anterior uveitis. Mol Vis. 2010;16:1448-52.

54. Theron AJ, Steel HC, Tintinger GR, Gravett CM, Anderson R, Feldman C. Cysteinyl leukotriene receptor-1 antagonists as modulators of innate immune cell function. J Immunol Res. 2014;2014:608930

55. Gonzalez-Pena D, Nixon SE, O'Connor JC, Southey BR, Lawson MA, McCusker $\mathrm{RH}$, et al. Microglia transcriptome changes in a model of depressive behavior after immune challenge. PLoS One. 2016. doi:10.1371/journal.pone.0150858.

56. Gregerson DS, Sam TN, McPherson SW. The antigen-presenting activity of fresh, adult parenchymal microglia and perivascular cells from retina. J Immunol Baltim Md 1950. 2004:172:6587-97.

\section{Submit your next manuscript to BioMed Central and we will help you at every step:}

- We accept pre-submission inquiries

- Our selector tool helps you to find the most relevant journal

- We provide round the clock customer support

- Convenient online submission

- Thorough peer review

- Inclusion in PubMed and all major indexing services

- Maximum visibility for your research

Submit your manuscript at www.biomedcentral.com/submit 